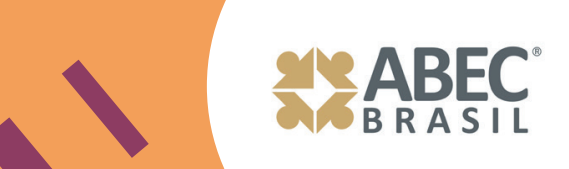

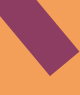

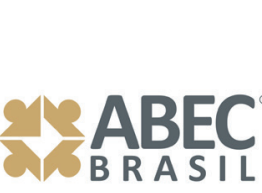
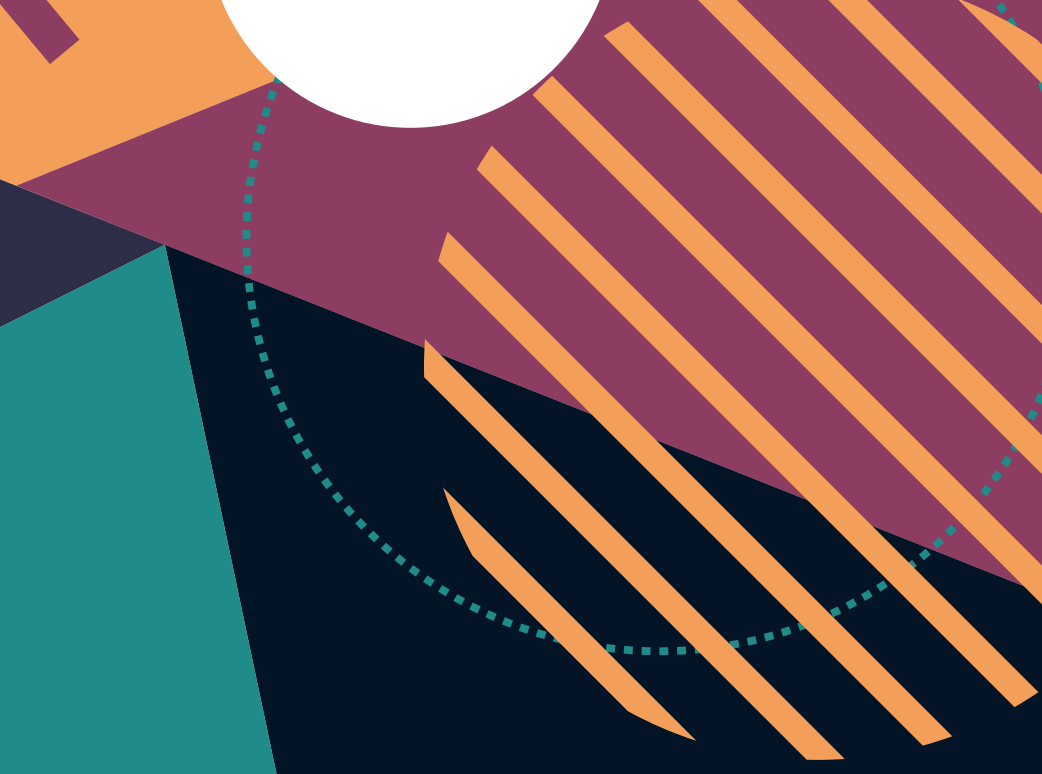

Ciência Aberta

Para Editores

Cientificos

Organizadores: Milton Shintaku, Luana Sales. 


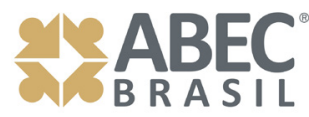

\title{
Ciência Aberta para Editores Científicos
}

\author{
Milton Shintaku \\ Luana Sales \\ Organizadores
}

São Paulo

2019 


\section{ASSOCIAÇÃO BRASILEIRA DE EDITORES CIENTÍFICOS}

\section{Diretoria}

Rui Seabra Ferreira Júnior (CEVAP/UNESP, Botucatu, SP)

Presidente

Ricardo Antunes de Azevedo (ESALQ/USP, Piracicaba, SP)

Vice-Presidente

Ana Marlene Freitas de Morais (IAE/DCTA, São José dos Campos, SP)

Secretário-Geral

Milton Shintaku (Ibict, Brasília, DF)

$1^{\circ}$ Secretário

Benedito Barraviera (FMB/UNESP, Botucatu, SP)

$1^{\circ}$ Tesoureiro

Suzana Caetano da Silva Lannes (FCF/USP, São Paulo, SP)

$2^{\circ}$ Tesoureiro

\section{Conselho Deliberativo - Membros Titulares}

Piotr Trzesniak (Universidade Federal de Itajubá, Itajubá, MG)

Elisabete Werlang (UFSC, Florianópolis, SC)

Bruna M. S. Erlandsson (Linceu Editorial, São José dos Campos, SP)

Eloísa da Conceição Príncipe de Oliveira (Ibict, Rio de Janeiro, RJ)

Elizabeth da Costa Mattos (Instituto de Aeronáutica e Espaço, São José dos Campos, SP)

Meryt Tarcila Teixeira Zanini (SBCCV, São Paulo, SP)

Germana Fernandes Barata (Núcleo de Desenvolvimento da Criatividade da Unicamp, Campinas, $\mathrm{SP})$

Gildenir Carolino Santos (Biblioteca Central da Unicamp, Campinas, SP)

Valtencir Zucolotto (Instituto de Física de São Carlos da USP, São Carlos, SP)

Vera Lúcia Gomes Klein (Instituto de Ciências Biológicas da UFG, Goiânia, GO)

\section{Conselho Fiscal - Membros Titulares}

Ilda Fontes (FGV-EAESP, São Paulo, SP)

David Matos Milhomens (Instituto Federal de Educação, Ciência e Tecnologia, Caxias do Sul, RS)

Neusa Maria Bastos Fernandes dos Santos (PUC-SP, São Paulo, SP) 


\title{
A
}

\section{Ciência Aberta para Editores Científicos}

\author{
Milton Shintaku \\ Luana Sales \\ Organizadores
}

São Paulo

2019 
(C) 2019 Associação Brasileira de Editores Científicos

Esta obra é licenciada sob uma licença Creative Commons - Atribuição CC BY 4.0, sendo permitida a reprodução parcial ou total, desde que mencionada a fonte.

\section{(๔) $(1)$}

Impresso no Brasil

Projeto Gráfico e Diagramação

Rafael Fernandez Gomes

Normalização

Ingrid Torres Schiessl

C569 Ciência aberta para editores científicos/ Milton Shintaku e Luana Sales (orgs.). -- Botucatu, SP: ABEC, 2019. --

$108 \mathrm{p}$.

ISBN 978-85-93910-02-9

DOI: $10.21452 / 978-85-93910-02-9$

1. Comunicação científica. 2. Software livre. 3.Acesso aberto. 4. Dados abertos. 5. Tecnologia da Informação. I. Shintaku, Milton (Org.). II. Sales, Luana (Org.). III. Título.

\section{$A B E C$}

(14) 3815.5095

abec@abecbrasil.org.br

doi@abecbrasil.org.br (das 07h30 às 17h30)

Rua Azaleia, 399 - Edifício 3 Office, $7^{\circ}$ Andar, Sala 75 - Bairro Chácara Floresta

CEP 18.603-550, Botucatu, SP 


\section{Agradecimentos}

- ste livro é fruto da colaboração de muitos, não apenas por ser uma - organização composto por muitos autores, mas porque traz a contribuição de pessoas que direta ou indiretamente atuaram na sua construção. A família que cede tempo e nos apoia a construir conhecimentos. Os amigos que sempre nos incentivam a continuar os estudos. A todas as palavras de carinho que recebemos, como um elogio longo ou um simples "bom trabalho". Tudo que nos faz seguir o caminho da pesquisa e a vontade de compartilhar nossos conhecimentos

Um agradecimento especial a todos os autores que participaram desse desafio de apresentar a ciência aberta aos editores científicos brasileiros, nos seus mais diversos aspectos. Da mesma forma que agradecemos a ABEC, por meio do seu Presidente Rui Seabra Jr, pela confiança depositada em organizar um livro com a liberdade que somente a ciência aberta permite.

A todos pela oportunidade em contribuir com este tema tão empolgante.

Os organizadores agradecem. 


\section{Sumário}

Agradecimentos $\quad 5$

$\begin{array}{ll}\text { Prefácio } & 7\end{array}$

Apresentação 9

1 A Ciência Aberta e a Necessidade de Novos Modelos de Publicação 11

2 Ciência Aberta: movimento de movimentos $\quad 15$

3 A Parceria para Governo Aberto e o Compromisso pela Ciência Aberta 21

4 Abertura da ciência e os editores científicos 29

5 Megajournal $\quad 35$

6 Diretórios de políticas editoriais sobre 0 acesso aberto 41

7 Comunicação na ciência aberta: depósito e disseminação de dados 51

8 A revisão por pares no contexto da Ciência Aberta: uma breve apresentação

90 caderno aberto de laboratório de Jean-Claude Bradley 67

10 Fast Track Publication: rapidez na comunicação cientifica 73

11 Plataformas e infraestruturas no contexto da pesquisa cientifica $\quad 79$

12 Publicações semânticas: melhorando comunicação entre homem e máquina

13 Ciências Abertas e Mídias do Conhecimento 93

14 Periódicos de resultados negativos: revelando uma parte invisivel da ciência 


\section{Prefácio}

o final do século $X X$, a partir das mudanças impostas pela evolução da Tecnologia da Informação e Comunicação (TIC), uma revolução começou a se desenhar também nas ciências. Primeiramente, com o advento da internet e de suas possibilidades, pode-se intercambiar documentos digitais, o que foi conhecido como Arquivos Abertos (Open Archives). Da mesma forma que, esta revolução causou uma crise nos periódicos, devido a um modelo de restrição de acesso por assinatura, fez surgir o movimento de acesso aberto à informação científica. Como resultado aos movimentos de abertura das ciências, culminamos agora com as ciências abertas.

O Ministério da Transparência e Controladoria Geral da União, em 2018, iniciou ações voltadas ao governo aberto, dentre os quais conta o Compromisso pela Ciência Aberta. Com isso, o governo federal tem buscado estabelecer mecanismos para incentivar a Ciência Aberta no Brasil, por meio da governança dos dados científicos. Assim, devemos criar uma grande articulação entre o governo e os atores envolvidos na geração de ciência em nosso país, objetivando o avanço da ciência aberta no Brasil, que também, de certa forma estará alinhado às necessidades governamentais.

Nesse contexto, a Associação Brasileira de Editores Científicos (ABEC Brasil), alinhada a esse movimento governamental, oferta a sua parcela 
de apoio, publicando textos e promovendo eventos que apresentam diversas ações da ciência aberta. Assim, aceitando ao convite para participar do Compromisso, a ABEC Brasil se compromete em articular ações com os editores científicos, inserir palestras em seus eventos, divulgar notícias em seus canais de comunicação social e produzir conteúdo que estimulem e divulguem a importância da Ciência Aberta.

Cabe destacar que a ABEC Brasil, desde a sua criação, em 28 de Novembro de 1985, tem atuado no apoio à melhoria das publicações científicas nacionais, com a oferta de informações relevantes e atualizadas com o melhor que ocorre no cenário internacional no que tange a publicação e editoração científica. Diante disso, a importância desta obra é fundamental na atualização dos editores e de seu staff editorial, face a um movimento que abre as ciências e impacta diretamente em todo o processo de criação e disseminação da informação científica.

\section{Rui Seabra Ferreira Jr}

Presidente da ABEC 


\section{Apresentação}

Presente livro é resultado do desafio apresentado pelo Compromis-
so pela ciência Aberta, apresentando pelo Ministério da Ciência, Tec-
nologia, Inovações e Comunicações (MCTIC), no marco seis, que visa a
articulação com os editores científicos brasileiros. Nesse sentido buscou
textos livres, sem uma linha editorial fechada, seguindo o próprio tema
da ciência aberta, em que estudiosos estão trilhando novos caminhos.

Nesse sentido, são doze textos apresentando aspectos da ciência aberta que possui relação direta ou indireta a editoração científica, com autores convidados pela atuação em diversas atividades e instituições. Com isso, buscou-se a pluralidade do tema, apresentando aspectos diversos, visto que a Ciência Aberta engloba uma revolução, que impacta os processos científicos tradicionais.

Assim, a Associação Brasileira de Editores Científicos (ABEC Brasil), alinhado com as tendências mundiais, procura atender os anseios dos membros e pessoas interessadas em editoração científica com informações sobre Ciência Aberta e editoração científica. Cumpre-se o papel da associação em discutir o estado da arte em publicação científica, contribuindo com discussões pertinentes a sua missão.

Atende-se, dessa forma, a necessidade dos editores por informações especificamente voltadas a eles, com oferta de uma obra escrita para 
esse público, de forma a mantê-los atualizados com as tendências das ciências, que podem impactar as suas atividades. Convida-se os editores e lerem e participarem da discussão sobre ciência aberta e a editoração científica, atuando de forma mais ativa na ABEC.

Boa Leitura!

Os Autores 


\title{
1 A Ciência Aberta e a Necessidade de Novos Modelos de Publicação
}

\author{
Luana Sales
}

Milton Shintaku

á algum tempo a comunidade científica sente a necessidade de novos modelos de publicações. Modelos que possam explicitar mais claramente a pesquisa desenvolvida, seus métodos, seu material, que revelem com nitidez a intenção do pesquisador e dos diversos projetos de pesquisa, que possam servir de base para avaliações mais confiáveis e para testes de veracidade e replicação de experimentos, ou simplesmente, estarem disponíveis para serem reutilizadas mais eficazmente para novas pesquisas. Modelos que não sejam apenas uma cópia eletrônica da página impressa, como é o documento PDF, mas que permitam ao pesquisador interagir com outros pesquisadores e também com os sistemas automatizados subjacentes às novas concepções de publicações.

No início do século XX, ainda muito aquém dos avanços tecnológicos recentes, Paul Otlet, pai da Documentação, já criticava o modelo tradicional de publicação científica e, em diversas palestras já mencionava 
a necessidade de um novo padrão de publicação (HEUVEL; RAYWARD, 2011). De acordo com estes autores, Otlet tinha plena consciência da necessidade de um novo formato para o livro que deveria ter por base uma forma colaborativa de representação do conhecimento.

Aparentemente o avanço tecnológico seria rapidamente apropriado pelas comunidades científicas possibilitando uma rápida transição para um novo modelo de publicação acadêmica, a exemplo do que vem acontecendo com os demais veículos de informação desde o surgimento da Web, entretanto, não foi isso que se observou. Desde meados da década de 90, o advento da Internet vem trazendo diversas oportunidades de melhoria dos canais de comunicação científica. As publicações on-line revolucionaram a pesquisa e a descoberta de informações, aumentando a amplitude e a facilidade de acesso a todo tipo de material, inclusive conjuntos de dados científicos. No entanto, quando se trata do artigo científico - enquanto principal veículo para comunicar pesquisa - as publicações apresentaram pouca melhoria, principalmente no que diz respeito à aplicação de tecnologias de Web 2.0 e Web semântica, que poderiam certamente beneficiar esse veículo em termos de representação, estrutura, organização e apresentação. Essa constatação pode ser evidenciada no primeiro texto de Kircz (2001) sobre novas práticas para publicação eletrônica, onde o autor mostra que não basta juntar informações, mas é preciso reuní-las sob um contexto para que possam servir de base para a argumentação entre os pares:

um documento eletrônico não é uma versão eletrônica de um documento tradicional em papel, com enfeites, como hiperlinks, fotos coloridas e animações ilustrativas. Em vez disso, um documento eletrônico é um documento que compreende uma variedade de diferentes tipos de informações que são apresentadas juntas por um autor, a fim de formular um argumento científico abrangente. (KIRCZ, 2001, p. 266). 
Segundo Aalbersberg, Dunham e Koers (2013), nas últimas décadas, as "melhorias no artigo acadêmico têm sido principalmente em termos de entrega (eletronicamente), descoberta (pesquisa de texto completo), bem como uma série de melhorias específicas, em menor escala, como a possibilidade de fazer upload de dados complementares". Entretanto, em termos de estrutura e forma, o artigo atual é, em geral, o mesmo que nas primeiras revistas científicas do século XVII. Com o intuito de estabelecer uma nova infraestrutura para disseminação e compartilhamento do conhecimento científıco que novos modelos de publicação que utilizem o máximo potencial tecnológico vêm sendo propostos.

A Ciência aberta - enquanto movimento internacional que vem advogando a abertura de publicações, dados de pesquisa, metodologias, códigos de softwares, ente outros - amplia a possibilidade de inovação não apenas nas pesquisas científicas, mas também na forma de comunicar a ciência. Neste sentido, é preciso considerar não apenas novos formatos de periódicos, mas também reconfigurar o amplo ciclo da comunicação científica, reformulando os métodos de avaliação e forma de apresentação dos resultados de investigação.

Dentro das perspectivas de compartilhamento e construção colaborativa de conhecimento, a Ciência aberta se apresenta como uma força que poderá permitir avanço científico como nunca já visto. Mas para que isso seja possível é preciso antes de tudo união entre os atores que compõem o cenário científico. É preciso que formuladores de política científicas, agências de fomento, editores científicos, pesquisadores e instituições de pesquisa se unam criando artifícios para impulsionar a Ciência Aberta de forma segura.

Muitos desses atores já vêm se articulando e a Parceria no Compromisso 3 do 4 Plano de Ação Nacional em Governo Aberto (Open Government Partniship) cujo a temática é dados abertos na Ciência é uma amostra 
dessa articulação. Assim, a pergunta que se coloca é: Como os editores científicos poderão colaborar com o movimento da Ciência aberta garantindo o seu protagonismo merecido? Este livreto traz à tona algumas das questões que merecem ser debatidas no âmbito dos fóruns de editores científicos.

\section{Referências}

AALBERSBERG, IJ. J.; DUNHAM, J.; KOERS, H. Connecting scientific articles with research data: New directions in online scholarly publishing. Data Science Journal, v. 12, n. May, p. 235-242, 2013.

HEUVEL, C. VAN DEN; RAYWARD, W. B. Facing Interfaces: Paul Otlet's Visualizations of Datalntegration. Journal of the American Society for Information Science \& Technology, v. 62, n. 12, p. 2313-2326, 2011.

KIRCZ, J. G. New practices for electronic publishing 1: Will the scientific paper keep its form? Learned Publishing, v. 14, n. 4, p. 265272, Oct. 2001. Disponível em:< https://onlinelibrary.wiley.com/doi/ pdf/10.1087/095315101753141365 >. Acesso em: 27 ago. 2019.. 


\section{Ciência Aberta: movimento de movimentos}

Sarita Albagli

termo ciência aberta designa, em linhas gerais, a ideia de que "o conhecimento científico deve ser livre para as pessoas usarem, reutilizarem e distribuírem sem restrições legais, tecnológicas ou sociais." ²(OPEN KNOWLEDGE FOUNDATION (OKF), [s.d.]).

O movimento pela ciência aberta foi impulsionado, de início, pelo movimento em favor do acesso aberto às publicações científicas, que despontou a partir da última década do século XX, em reação aos elevados preços praticados pelas editoras comerciais. Este período coincidiu com o endurecimento dos regimes de proteção da propriedade intelectual e, logo, da privatização do conhecimento. Ao mesmo tempo,

1 Pesquisadora do IBICT. Professora do Programa de Pós-Graduação em Ciência da Informação IBICT-UFR]

2 No original: "Open science means many things, but primarily scientific knowledge that people are free to use, re-use and distribute without legal, technological or social restrictions." 
constituíam-se condições sem precedentes, propiciadas pelas novas plataformas digitais, a internet em particular, em favor da abertura e do compartilhamento do conhecimento. Tornava-se assim evidente a inadequação de obstáculos artificiais, especialmente legais e econômicos, à livre circulação da informação científica, dificultando a difusão dos resultados da pesquisa e, logo, o avanço da ciência, sobretudo aquela financiada com recursos públicos. Supõe-se que a abertura da ciência permite maior produtividade, qualidade e retorno social da pesquisa, maximizando resultados e diminuindo redundância, facilitando a colaboração e a reprodutibilidade.

À medida em que o movimento pela ciência aberta avança, incorporam-se novos elementos à sua agenda, ampliando seu escopo e conferindo-Ihe novos significados. Ela engloba desde a disponibilização aberta dos resultados da pesquisa, até a valorização e a participação direta de não cientistas no fazer ciência.

Ciência aberta pode ser então entendida como um "movimento de movimentos", ou seja, um processo em construção, que abriga várias vertentes, tais como publicações científicas abertas, dados abertos de pesquisa, ferramentas científicas abertas (software e hardware), cadernos de pesquisa abertos e ciência cidadã (ALBAGLI; CLINIO; RAYCHTOCK, 2014). Logo, mais do que um termo "guarda-chuva", a ciência aberta avança no sentido de integrar essas várias frentes, ampliando a questão do acesso para as novas formas colaborativas de produção e circulação da informação e do conhecimento em ciência, bem como sua apropriação social.

A ideia de abertura na ciência mobiliza assim interesses e pontos de vista diversos e permite múltiplas interpretações. Por um lado, trata-se de aumentar a velocidade da pesquisa científica, bem como a visibilidade e o acesso a seus resultados. Por outro, trata-se também de aumentar a base social da ciência, conferindo maior porosidade na sua relação e 
interlocução com outros tipos de saberes e atores sociais e cognitivos. Em síntese, ciência aberta não se restringe à abertura no âmbito estrito do campo científico, numa perspectiva eminentemente pragmática ou instrumental. Envolve também o reconhecimento da contribuição e o diálogo com outros atores e espaços de conhecimento, colocando em questão o tipo de ciência que se produz, numa perspectiva democrática (ALBAGLI, 2015).

A adoção e a difusão da ciência aberta envolvem diferentes atores e níveis de intervenção:

a. o pesquisador individual e suas práticas e estratégias de pesquisa, bem como de compartilhamento de resultados;

b. o ambiente mesoinstitucional, suas políticas, normas e infraestruturas, tais como instituições de ensino e pesquisa, editoras públicas e privadas de publicações acadêmicas (sobretudo de periódicos científıcos), agências de financiamento, avaliação e certificação;

c. o macroambiente institucional, em âmbitos nacional e internacional, incluindo o aparato legal que dispõe sobre o regime de propriedade intelectual e o acesso à informação, entre outros aspectos.

Cruciais são os critérios e métricas de avaliação da qualidade da pesquisa, bem como seus desdobramentos sobre os critérios de progressão na carreira científica e de concessão de recursos financeiros e materiais para a ciência. A disponibilidade de ferramentas e infraestruturas para a pesquisa colaborativa e a livre circulação de seus resultados é também estratégica, assim como os respectivos regimes jurídico-institucionais. Destacam-se ainda as condições para recuperação, acesso e reuso desses materiais, envolvendo disponibilidade de dados e metadados, leitura por máquinas e interoperabilidade, entre outros. 
Tudo isso requer conhecimento e capacidade para operar os novos aparatos instrumentais e atender aos novos requisitos institucionais da ciência aberta. São também múltiplas as dimensões que exercem influências recíprocas na sua adoção e difusão - (geo)políticas, econômicas, culturais, institucionais, técnicas, éticas --, devendo ser consideradas particularmente as implicações das assimetrias nas relações de poder entre os vários atores.

Nesse cenário, a ciência aberta coloca novas pautas e questões para a comunicação científica (APPEL; ALBAGLI, 2018). Os periódicos científicos, em especial, são desafiados a renovarem suas práticas, critérios e formatos, considerando aspectos como: acesso aos dados; revisão aberta entre pares; outros critérios de qualificação da pesquisa; rediscussão das métricas; adoção de formatos mais amigáveis à recuperação de conteúdos e metadados das publicações; atribuição de (co)autoria e reconhecimento da contribuição de cientistas cidadãos; infraestruturas abertas, entre outros.

A configuração de novos modelos de negócio repercute na ampliação do espectro de modalidades de acesso aberto. Assim, a via dourada passa a incluir também o acesso aberto via cobrança de taxas para autores, enquanto a via diamante indica a inexistência qualquer cobrança. O autoarquivamento pós publicação, em repositórios e afins (via verde), ganha nova proeminência, ainda que frequentemente sujeito a períodos de embargo.0 papel dos preprints é revalorizado como meio de agilizar a disseminação dos resultados da pesquisa. Por outro lado, o acesso aberto por meio da quebra de direitos comerciais e de propriedade intelectual (via negra) continua a expandir-se.

Despontam ainda outros de formatos e meios de comunicação da ciência que reforçam seu caráter aberto, valendo-se das novas possibilidades multimídias e colocando em questão a centralidade dos periódicos. 
Trata-se, portanto, de um processo em plena transformação, que impõe inovações de toda ordem nos modos de produzir, compartilhar e difundir ciência.

\section{Referências}

ALBAGLI, S. Ciência aberta em questão. In: ALBAGLI, S.; MACIEL, M.; ABDO, A. (Eds.). . Ciência aberta, questões abertas. Brasília: IBCIT, 2015. p. 9-26. Disponível em: <http://livroaberto.ibict.br/handle/1/1060>. Acesso em: 16 jun 2019.

ALBAGLI, S.; CLINIO, A.; RAYCHTOCK, S. Ciência Aberta: correntes interpretativas e tipos de ação. Liinc em Revista, v. 10, n. 2, p. 434450, 5 dez. 2014. Disponível em: <http://revista.ibict.br/liinc/article/ view/3593/3072>. Acesso em: 16 jun 2019.

APPEL, A. L.; ALBAGLI, S. Dimensões tecnopolíticas e econômicas da comunicação científica em transformação. XIX ENCONTRO NACIONAL DE PESQUISA EM CIÊNCIA DA INFORMAÇÃO - ENANCIB. Anais... Londrina: ANCIB, 2018. Disponível em: <http://enancib. marilia.unesp.br/index.php/ XIXENANCIB/xixenancib/paper/view/1298>. Acesso em: 27 ago. 2019.

OPEN KNOWLEDGE FOUNDATION (OKF). Open Science Working Group. Disponível em: <http://science.okfn.org/\#sthash.ZOMzf8Fg.dpuf>. Acesso em: 19 ago. 2019. 



\section{A Parceria para Governo Aberto e o Compromisso pela Ciência Aberta}

Juliana Meireles Fortaleza

Patrícia Rocha Bello Bertin

0 movimento do Governo Aberto se refere a uma nova visão da administração pública que promove projetos e ações voltados ao aumento da transparência, à luta contra a corrupção, ao incentivo à participação social e ao desenvolvimento de novas tecnologias, contribuindo para o estabelecimento do vínculo entre a sociedade e os tomadores de decisão. Em 2000, com a criação da Lei de Responsabilidade Fiscal (Lei Complementar n 101/2000) foi criado o paradigma da transparência na gestão pública brasileira que levou o país a promover uma série de mudanças legais e administrativas. Desde então, vêm sendo publicadas normas que regulamentam e orientam os órgãos da administração pública a lidar com a abertura de dados, como a Infraestrutura Nacional de Dados Espaciais (INDE - Decreto Presidencial n 6.666/2008), a Lei de Acesso à Informação (LAl - Lei no 12.527/2011), a Política de Dados Abertos do Poder Executivo Federal (Lei n 8.777/2016) e, mais recentemente, a Lei Geral de Proteção de Dados (LGPD - Lei nº 13.709/2018) e 
a Política Nacional de Segurança da Informação (Decreto nº 9.367/2018). Aliada a essas normas, o Brasil foi um dos cofundadores, juntamente com a África do Sul, Filipinas, Estados Unidos, Indonésia, México, Noruega e Reino Unido, da iniciativa internacional Parceria para Governo Aberto (Open Government Partnership - OGP), criada em 2011, com o objetivo de difundir e incentivar globalmente os princípios do governo aberto que são transparência, accountability, participação social e inovação e tecnologia. Para que um país se torne um dos integrantes da OGP é necessário que ele atenda aos critérios de elegibilidade, que são: transparência fiscal, acesso à informação, participação cidadã e divulgação de declarações patrimoniais das autoridades. Atendendo a esses critérios, o país endossa a Declaração de Princípio da OGP e inicia o seu processo de construção do Plano de Ação Nacional, que tem vigência de dois anos. Atualmente, mais de 75 países participam com essa iniciativa. Cada um deles constrói seus Planos de Ação Nacionais compostos por compromissos de Estado, os quais devem estar de acordo com os princípios de governo aberto, cujas ações assumidas pelo país junto à Parceria devem ser específicas, mensuráveis, relevantes, factíveis e delimitadas no tempo durante o período de vigência do Plano.

O Brasil publicou, em outubro de 2018, o seu $4^{\circ}$ Plano de Ação Nacional em Governo Aberto (Ministério da Transparência e Controladoria-Geral da União, 2018) composto por 11 compromissos, entre eles o Compromisso 3 - o Compromisso pela Ciência Aberta - que tem o objetivo de 'estabelecer mecanismos de governança de dados científicos para o avanço da Ciência Aberta no Brasil'. Esse compromisso foi construído conforme metodologia elaborada pelo Grupo-Executivo da Parceria para Governo Aberto no Brasil - coordenado pelo Ministério da Transparência e Controladoria-Geral da União - e pelo GT da Sociedade Civil. Essa metodologia é aplicada desde o $3^{\circ}$ Plano de Ação e vem sendo referência para a construção dos planos de outros países e é constituída por três 
etapas: i) Definição de Temas; ii) Ofıcinas de Cocriação; e iii) Aprovação do Plano (Figura 3.1).

Figura 3.1 - Etapas previstas na metodologia de cocriação dos planos de ação.

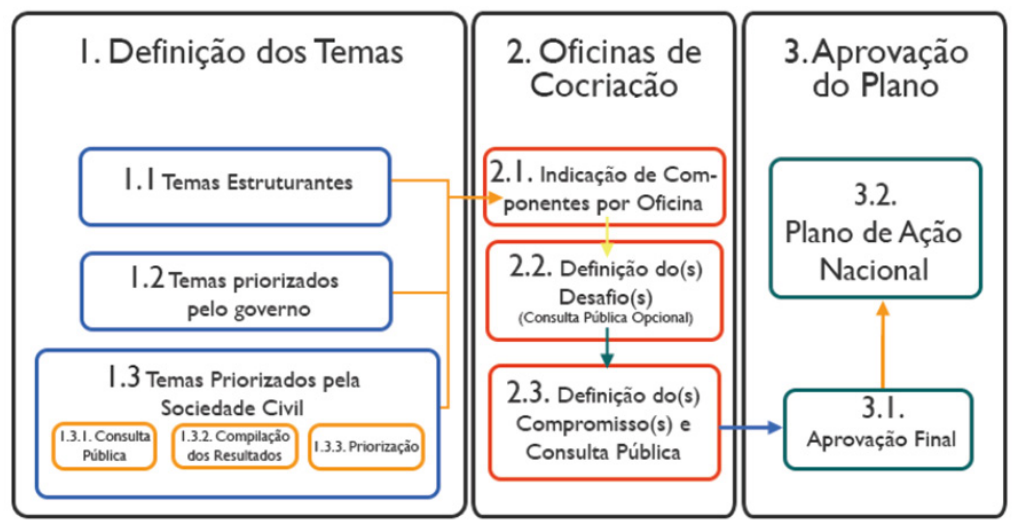

Fonte: BRASIL (2018).

A primeira etapa consiste na definição dos temas, que são categorizados em estruturantes, priorizados pelo governo e priorizados pela sociedade civil. Os temas estruturantes envolvem assuntos, que por sua própria natureza, têm a possibilidade de potencializar as políticas de Governo Aberto no Brasil. Os temas priorizados pelo governo são aqueles de importância estratégica para o Governo Federal, os quais são propostos pelos órgãos da administração pública federal em resposta à consulta do Ministério da Transparência e Controladoria-Geral da União. Enquanto os temas priorizados pela sociedade civil em que a sociedade sugere os temas considerados importantes e que devem ser tratados por meio de políticas de Governo Aberto. As propostas de temas são feitas por meio de consulta pública, para posterior compilação e nova consulta pública para votação. A segunda fase é a realização das oficinas de cocriação que são reuniões onde se materializa o trabalho 
colaborativo entre governo e sociedade por meio de um amplo debate entre especialistas em cada um dos temas priorizados. Finalmente, a terceira fase consiste na aprovação do Plano de Ação pela sociedade por meio de consulta pública e posterior publicação.

O tema proposto pela Embrapa, Inovação e Governo Aberto na Ciência, foi um dos priorizados pelo Governo e está alinhado com o Objetivo 9.5 para o Desenvolvimento Sustentável, referente ao fortalecimento da pesquisa científica e incentivo à inovação, sendo que uma das formas de atingir esse objetivo é por meio da Ciência Aberta. O conceito de Ciência Aberta está em amadurecimento e consolidação. Esse novo paradigma da ciência prevê uma ciência colaborativa, em que os dados de pesquisa são disponibilizados gratuitamente para reuso, redistribuição, reprodutibilidade, rastreabilidade, acessibilidade e verificabilidade. Ações essas que conduzem a pesquisa para o caminho da transparência, para o aumento da produtividade científica, para o incentivo à inovação e à participação social por meio da Ciência Cidadã, que é um dos pilares da Ciência Aberta.

A construção do Compromisso pela Ciência Aberta ocorreu em duas oficinas de cocriação e contou a parceria de outros órgãos do governos e da sociedade civil, entre eles: Ministério da Ciência, Tecnologia, Inovações e Comunicações (MCTIC), Fundação Oswaldo Cruz (Fiocruz), Instituto Brasileiro de Informação em Ciência e Tecnologia (Ibict), Conselho Nacional de Desenvolvimento Científico e Tecnológico (CNPq), Coordenação de Aperfeiçoamento de Pessoal do Nível Superior (Capes), Rede Nacional de Ensino e Pesquisa (RNP), Programa SciElo/FAPESP, Associação Brasileira de Editores Científicos (ABEC), Universidade de Brasília (UnB) e Open Knowlegde Brasil (OKBR). Para o cumprimento desse compromisso, que é coordenado pela Embrapa, foram construídos nove marcos (ações) para a sua execução, com seus respectivos prazos e órgãos responsáveis e colaboradores (Quadro 3.1). 
Quadro 3.1 - Marcos verificáveis e mensuráveis para o cumprimento do compromisso.

\begin{tabular}{|c|c|c|c|}
\hline Marcos & Data de inicio & Data de conclusão & Responsáveis \\
\hline $\begin{array}{l}\text { 1-Implantação de uma rede } \\
\text { interinstitucional pela Ciência } \\
\text { Aberta }\end{array}$ & $01 / 10 / 2018$ & $31 / 03 / 2019$ & $\begin{array}{l}\text { MCTIC* }^{*} \\
\text { Embrapa } \\
\text { IBICT } \\
\text { Fiocruz }\end{array}$ \\
\hline $\begin{array}{l}2 \text { - Realização de diagnóstico } \\
\text { nacional e internacional da } \\
\text { Ciência Aberta }\end{array}$ & $01 / 10 / 2018$ & $31 / 03 / 2019$ & $\begin{array}{l}\text { UnB* } \\
\text { Fiocruz } \\
\text { RNP }\end{array}$ \\
\hline $\begin{array}{l}3 \text { - Definição de diretrizes e } \\
\text { principios para políticas ins- } \\
\text { titucionais de apoio à Ciência } \\
\text { Aberta }\end{array}$ & $01 / 11 / 2018$ & $30 / 11 / 2019$ & $\begin{array}{l}\text { IBICT }^{*} \\
\text { MCTIC } \\
\text { Fiocruz } \\
\text { Embrapa }\end{array}$ \\
\hline $\begin{array}{l}4 \text { - Promoção de ações de } \\
\text { sensibilização, participação e } \\
\text { capacitação em Ciência Aber- } \\
\text { ta }\end{array}$ & $01 / 11 / 2018$ & $31 / 07 / 2020$ & $\begin{array}{l}\text { Fiocruz* } \\
\text { IBICT } \\
\text { CAPES } \\
\text { Embrapa }\end{array}$ \\
\hline $\begin{array}{l}5 \text { - Articulação com agências } \\
\text { de fomento para a implanta- } \\
\text { ção de ações de apoio à Ciên- } \\
\text { cia Aberta }\end{array}$ & 01/03/2019 & $31 / 03 / 2020$ & $\begin{array}{l}\text { CNPq* }^{*} \\
\text { CAPES } \\
\text { Embrapa }\end{array}$ \\
\hline $\begin{array}{l}6 \text { - Articulação com editores } \\
\text { científicospara a implantação } \\
\text { de ações em apoio à Ciência } \\
\text { Aberta }\end{array}$ & 01/03/2019 & $31 / 03 / 2020$ & $\begin{array}{l}\text { ABEC* } \\
\text { SCIELO/ } \\
\text { FAPESP } \\
\text { IBICT } \\
\text { CAPES }\end{array}$ \\
\hline $\begin{array}{l}7 \text { - Implantação de infraestru- } \\
\text { tura federada piloto de repo- } \\
\text { sitórios de dados de pesquisa }\end{array}$ & 01/01/2019 & $30 / 06 / 2020$ & $\begin{array}{l}\text { RNP* } \\
\text { CNPq } \\
\text { IBICT }\end{array}$ \\
\hline $\begin{array}{l}8 \text { - Proposição de padrões de } \\
\text { interoperabilidade para repo- } \\
\text { sitórios de dados de pesquisa }\end{array}$ & $01 / 11 / 2018$ & $31 / 03 / 2020$ & $\begin{array}{c}\text { IBICT* }^{*} \\
\text { Open Know- } \\
\text { ledge } \\
\text { RNP } \\
\text { CNEN }\end{array}$ \\
\hline
\end{tabular}




\section{Marcos}

9 - Proposição de conjunto de indicadores para aferição da maturidade em Ciência Aberta
Data de inicio



01/09/2019
Data de conclusão

Responsáveis

Embrapa*

$31 / 07 / 2020$

Open Know-

ledge

CNPq

* Órgão/entidade responsável por coordenar a execução do marco.

Fonte: Elaboração dos autores (2019).

A Parceria para Governo Aberto abriu um espaço onde os diversos atores da comunidade científica se encontram para discutir e pôr em prática os mecanismos de governança dos dados de pesquisa que contribuam para o avanço da Ciência Aberta no Brasil. Espera-se que, ao final do $4^{\circ}$ Plano de Ação Nacional, as ações desenvolvidas em cada um dos marcos do Compromisso pela Ciência Aberta possam trazer novas ações e perspectivas para a Ciência Aberta no Brasil e demonstre ao Governo Federal e à sociedade que o tema é prioridade para o avanço da ciência brasileira.

Para saber mais e acompanhar as ações do Compromisso pela Ciência Aberta acesse a wiki da Ciência Aberta OGP Brasil .

3 Disponível em: <https://wiki.rnp.br/display/OGPBrasil> 


\section{Referência}

BRASIL. Ministério da Transparência e Controladoria-Geral da União. $4^{\circ}$ Plano de Ação Nacional em Governo Aberto. Brasília, DF. 2018. 55 p. Disponível em: <http://governoaberto.cgu.gov.br/no-brasil/planos-de-acao/4o-plano-de-acao-brasileiro/4o-plano-de-acao-nacional_portugues.pdf>. Acesso em: 19 ago. 2019. 



\section{Abertura da ciência e os editores científicos}

Milton Shintaku

Rui Ferreira Seabra Jr

esde a publicação do Journal de Savants e do Philosophical Transactions, ainda no século XVII, as revistas científicas se ajustaram às mudanças no sistema de publicação e na evolução da ciência. Se no início a impressão e distribuição eram desafios, aos poucos, essas barreiras foram transpassadas. Da mesma forma em que as revistas iam ganhando um formato com números, volumes e artigos, em um processo editorial que inclui editores e avaliação pelos pares, culminando em um modelo aceito por todos.

Com o surgimento do digital outros desafios se apresentaram, impactando a publicação das revistas científicas, mesmo que algumas revistas ainda não utilizam todas as facilidades oferecidas por esse novo suporte. Pode-se dizer que atualmente todas as revistas possuem sua versão digital, sendo que muitas já nasceram eletrônicas e outras tantas não possuem mais a versão impressa. 
Assim, como a mudança do suporte do físico para o digital, a ciência vem mudando, em particular na chamada comunicação científica, trazendo mudanças na publicação científica, que trata da disseminação da informação científica entre os seus diversos atores. Assim, envolve a comunicação entre os pares, por meio de publicações e apresentações em eventos, entre outras formas de comunicação.

Historicamente, depois do estabelecimento da prensa e dos chamados publishers, possivelmente a primeira grande novidade, impulsionada pelo modelo digital na comunicação científica pode ser considerado o surgimento do ArXiv em 1991. Nesta iniciativa, muito ligada às ciências rígidas e engenharias, os autores podiam publicar o seus pré-prints, de forma a deixá-los online e aberto ao acesso de todos. Os textos disponibilizados no ArXiv são moderados por especialistas, mas não avaliados pelos pares, podendo ser publicados em revistas científicas posteriormente, mesmo que alguns autores não o façam. Assim, editores das áreas cobertas pelo ArXiv publicam as versões avaliadas pelos pares, pós-prints dos textos disponíveis no ArXiv.

Outro ponto de destaque ainda na década de 90 do século passado foi a criação do Digital Object Identifier (DOI), ficando como responsável a International DOI Foundation (IDF) em 1997. Assim o DOI torna-se o identificador unívoco do conteúdo, principalmente digitais em rede. Este ponto impactou os editores científicos, visto a necessidade em adotar esse identificador para a revista e os artigos publicados. No Brasil, a agência principal que oferta o DOI é a CrossRef, por meio de um acordo com a Associação Brasileira de Editores Científicos (ABEC).

Em 1999 surgem dois movimentos que são confundidos por seus nomes e semelhanças. O Movimento do Acesso Aberto (Open Access) e o Arquivos Abertos (Open Archives). De forma simplista, pode-se dizer que a principal característica do Acesso Aberto repousa no acesso livre 
ao conhecimento científico, enquanto os Arquivos Abertos se preocupam com a interoperabilidade dos metadados. Assim o Acesso aberto é mais político e filosófico, enquanto os Arquivos abertos são mais técnicos e tecnológicos.

Assim, pode-se afirmar que o Acesso Aberto teve um impacto maior nas publicações científicas, visto que algumas revistas se tornaram de acesso aberto, principalmente ao se estabelecerem como totalmente digital. Com isso, alterou-se o modelo de negócio, na medida em que pode-se adotar o modelo do Article Processing Charge (APC), no qual o autor paga pela publicação e com isso mantém-se a sustentabilidade da publicação.

Cabe destacar no Brasil o Scientific Eletronic Library Online (SciELO), que foi a primeira iniciativa a adotar o Acesso Aberto e Arquivo Aberto, ofertando DOI a seus membros, em um modelo que transcende ao país, sendo implementado e, vários outros. Devido às políticas de indexação implementadas pela SciELO, atualmente é considerado como fator de qualidade ser uma revista pertencentes à esta biblioteca online.

Softwares de apoio a publicações e revistas, como o Open Journal System (OJS) estão preparadas para atender a questões relacionadas a pré-prints, DOI, Acesso Aberto e Arquivos Abertos. O Brasil é o maior usuário desse sistema, com mais de 1.600 revistas implementadas nesta ferramenta, muito pela ação do Instituto Brasileiro de Informação em Ciência e tecnologia (IBICT), com os seus serviços de apoio e suporte.

Outro ponto de destaque como mudança na comunicação científica está nos Dados Abertos, que estimula o depósito dos dados de pesquisa em repositórios, disponibilizando-os para outros estudos. Assim, ao publicar os resultados de pesquisa, em uma revista, indica-se onde estão dos dados, para que sejam encontrados e indexados; disponíveis em formatos 
apropriados e abertos e; sem impeditivos legais. Editores que adotam os dados abertos alteram as políticas das revistas, de forma a requerer aos autores que depositem os dados dos artigos a serem publicados e indiquem a sua localização no texto e metadados.

A abertura gradual das atividades relacionadas à comunicação científica culmina na criação da Ciência Aberta, que agrega muitos dos preceitos dos movimentos anteriores, como se fosse uma evolução natural das práticas científicas, ante a presença maciça de tecnologias. Como exemplo, pode-se destacar como a comunicação entre cientistas mudou com a tecnologia, eliminando barreiras geográficas, fomentando a colaboração, tanto que atualmente há poucas publicações com autores únicos. Pesquisas podem ser feitas de forma distribuída, com a atuação de estudiosos de vários países e institutos de pesquisa e ensino.

A Ciência Aberta é um guarda-chuva que envolve várias vertentes, na medida em que se apresenta como um caminho para a democratização da ciência, com mudanças no modus operandi de várias atividades. Assim, fomenta uma filosofia aberta, que possui implicações nas atividades da pesquisa, desde questões prática e teóricas como a questão do Hardware e Software livres, ciência cidadã e questões educacionais abertas. Engloba preceitos já estabelecidos do acesso aberto, dados abertos e arquivos abertos, adicionado outros de forma a ampliar a sua atuação em áreas não tradicionais da ciência.

Nesse contexto, O Editor Científico deve prospectar, selecionar e analisar tendências de publicação, de forma a atualizar as políticas editoriais de revistas, no qual pode-se destacar, conforme as informações anteriores:

a. decidir se publica ou não textos disponibilizados como pré-prints em repositórios ainda não avaliados pelos pares. assim diferindo entre a versão inicial do autor e a versão final mediada pelo editor; 
b. adotar o Acesso Aberto ao artigos publicados, como sistema de sustentabilidade baseados nos vários tipos de APC, que pode ser a cobrança pela submissão, avaliação ou publicação, com as possíveis combinações, assim como valores;

c. requerer a disponibilização dos dados de pesquisa em repositórios de dados para os artigos aceitos para publicação;

d. adotar formas diferenciadas de avaliação para publicação, com a participação maior de interessados pelo tema dos textos a serem publicados, até mesmo a abertura da avaliação, com avaliação aberta pelos pares, de forma que avaliador e avaliado possam dialogar;

e. adotar políticas de publicação mais flexíveis, sem exigências de formação para submissões, com alinhamento aos princípios da ciência cidadã, voltadas aos cientistas amadores, em que o conteúdo torna-se o foco;

f. abrir espaço de interação com a sociedade nas revistas, ou mesmo com a permissão para os comentários mediados aos textos publicados.

Em todos os casos, nota-se a necessidade de reavaliação das políticas editoriais das revistas, com adoção de mudanças ante ao digital. Requer posições dos editores nas várias mudanças ocorridas no cenário editorial científico, que pode interferir nas políticas estabelecidas, principalmente em revistas mais tradicionais, nascidas na era impressa. 



\section{MegaJournal}

Milton Shintaku

Rui Ferreira Seabra Jr.

mudança do impresso para o digital tem influenciado drasticamente as atividades de publicação científica. Tanto que, na virada do século, Hurd (2000) previu uma grande mudança na comunicação científica a ser consolidado em 2020, no qual a tecnologia teria papel fundamental em todos os processos da pesquisa, sendo mais visível na disseminação dos resultados, no qual ocorreria apenas no formato digital.

Esse prognóstico tem se firmado, tanto que Welzenbach (2015) revela que em 2015 cerca de 44 mil menções à artigos científicos eram feitos diariamente e que, pelo menos 50 mil artigos eram compartilhados por semana. Esses números demonstram a força da web na comunicação científica, resultante do aumento das pesquisas e da necessidade de publicação de resultados, em canais formais, principalmente em acesso aberto.

Nesse cenário ainda em mutação, em que muitas revistas ainda estão se ajustando ao modelo totalmente digital e de acesso aberto, de forma a atender a mudanças nas práticas científicas e modelos de negócio, Binfield (2011) apresenta o Public Online Of Science (Plos) ONE, uma iniciativa inovadora denominada de MegaJournal. Por ainda ser uma 
iniciativa relativamente nova, no Brasil não há um consenso na sua nomenclatura, sendo denominada de MegaRevista por estudiosos como Momen (2013), ou como MegaPeriódicos por Shintaku et al (2019).

Assim, MegaJournal ainda requer estudos que o aporte conceitualmente, assim como a divulgação desse canal, que pode ser visto como uma evolução das revistas tradicionais. Mesmo que com certas restrições, Lópes-Borrull (2014) comparam os MegaJournals aos repositórios temáticos pela quantidade de documentos disseminados, como uma convergência da via dourada e verde do acesso aberto.

Bjork e Catani (2015), por sua vez, caracteriza o MegaJournal pelo grande volume de artigos publicados, com grande cobertura temática, publicando em acesso aberto com implementação de Article Processing Charge (APC), que dá celeridade ao processo editorial. Spezi et al (2017), por sua vez, acrescenta que os MegaJournal requerem publisher de prestígio, publicação de estudos que utilizam dados já utilizados e uso da altimetria como métrica para verificar impacto. Para os dois estudiosos, destacam a celeridade na publicação, ante ao grande número de submissões.

Em um cenário totalmente digital, em que todas as atividades são efetuadas neste suporte, Burns (2015) advoga que o MegaJournal pode ofertar indicadores que ajudam a entender a comunicação científica atual, com o uso de novas tecnologias. Nesse sentido, MegaJournal pode ser útil a novas métricas, tanto que Shintaku et al (2019) discute o uso da altimetria como forma natural de análise do impacto desse tipo de publicação. Domnina (2016) destaca a interdisciplinaridade desse canal de disseminação, tanto que o compara a repositórios pela amplitude de domínio temático.

O MegaJournal nasce dentro do movimento de Acesso Aberto ao conhecimento científıco, mas Lăzăroiu (2017) afirma que pode ser utilizado para disseminação restrita ao pagamento de assinatura, pois possuem políticas 
mais flexíveis, com alta diversidade de formas de APC. Assim, pela necessidade dos autores em publicar resultados de pesquisas cada vez mais rápido, Björk e Catani (2018) e Wakeling et al (2019) descrevem o MegaJournal como uma possibilidade de atender a demanda atual por publicação.

MegaJournal ainda não está estabelecido completamente, visto as desconfianças por parte de muitos acadêmicos ante aos periódicos predatórios. Entretanto, Guédon et al (2019) afirma que o MegaJournal pode ser um caminho para o movimento de acesso aberto. Nesse mesmo sentido, Hawkins (2019) estende esse preceito para a Ciência Aberta, visto a necessidade de canais mais adequados a essa nova tendência da ciência.

Cabe destacar a urgente necessidade de acomodação dos canais de comunicação às mudanças impostas pelas mudanças nas atividades científicas, com movimentos de abertura, não apenas do acesso aos resultados de pesquisa, mas da sua própria execução, como na ciência cidadã. Por fim, entende-se que os MegaJournal se apresentam como uma inovação dos periódicos científicos ante as mudanças da ciência no contexto digital, podendo ser uma resposta às inquietações mais atuais.

\section{Referências}

BINFIELD, P. PLoS ONE and the rise of the Open Access MegaJournal. PLoS, 2011. Disponível em: <https://www.nii.ac.jp/sparc/en/event/2011/ pdf/20120229_doc3_binfield.pdf>. Acesso em: 20 abr. 2018.

BJÖRK, B.-C.; CATANI, P. Evolution of the scholarly mega-journal, 20062017. PeerJ, v. 6, p. e4357, 2018. Disponível em: < https://peerj.com/ articles/4357/>. Acesso em: 19 abr. 2018. 
BJÖRK, B.-C.; CATANI, P. Have the "mega-journals" reached the limits to growth?. PeerJ, v. 3, p. e981, 2015. Disponível em: <https://peerj.com/ articles/981/>. Acesso em: 20 abr. 2018.

BURNS, C. S. Characteristics of a megajournal: a bibliometric case study. J Inf Sci: Theory Pract. Korea Institute of Science and Technology Information, v. 3,p. 16-30, 2015.

DOMNINA, T. N. A megajournal as a new type of scientific publication. Scientific and Technical Information Processing, v. 43, n. 4, p. $241-$ 250, 2016. Disponível em: <https://link.springer.com/article/10.3103\%2FS0147688216040079>. Acesso em: 22 abr. 2018.

COMISSÃO EUROPEIA. Diretoria-Geral de Pesquisa e Inovação. Future of scholarly publishing and scholarly communication: report of the expert group to the European Commission. 2019. 58 p. Disponível em:<https:// doi.org/10.2777/836532>. Acesso em: 27 ago. 2019.

HAWKINS, Donald T. Don's Conference Notes-Striking A Balance: The 39th SSP Annual Meeting. Against the Grain, v. 29, n. 5, p. 28, 2019.

HURD, J. M. The transformation of scientific communication: A model for 2020. Journal of the Association for Information Science and Technology, v. 51, n. 14, p. 1279-1283, 2000. Disponível em: <https://onlinelibrary. wiley.com/ doi/full/10.1002/1097-4571\%282000\%299999\%3A9999\%3C\%3A\%3AAID-ASI1 044\%3E3.0.CO\%3B2-7>. Acesso em: 22 abr. 2018.

WELZENBACH, R. Publishers: Michigan: Slide, 2015. 17 slides, color. Disponível em: <https://deepblue.lib.umich.edu/handle/2027.42/111641>. Acesso em 19 ago. 2019. 
LĂZĂROIU, G. Do mega-journals constitute the future of scholarly communication?. Educational Philosophy and Theory. 2017. Disponível em: <https://www.tandfonline.com/doi/full/10.1080/00131857.201 7.1300022>. Acesso em: 19 abr. 2018.

LÓPEZ-BORRULL, A. Megajournals, ¿hacia la posible fusión de revistas y repositorios?. Anuario ThinkEPI 2014, v. 8, p. 203-206, 2014. Disponível em: <http://eprints.rclis.org/23318/>. Acesso em: 18 abr. 2018.

MOMEN, H. Megarevistas e outras inovações na edição de revistas acadêmicas. Comunicação apresentada em 23.10.213, em Conferência Scielo 15 anos (no prelo)

SHINTAKU, Milton et al. Mega-Periódicos e altmetria: aproximações entre novas formas de publicação e de avaliação de impacto de resultados de pesquisa. Encontros Bibli: revista eletrônica de biblioteconomia e ciência da informação, v. 24, n. 54, p. 52-61, 2019.

SPEZI, V. et al. Open-Access mega-journals: the future of scholarly communication or academic dumping ground? A review. Journal of Documentation, v. 73, n. 2, p. 263-283, 2017. Disponível em: <https://www.emeraldinsight. com/doi/full/10.1108/JD-06-2016-0082>. Acesso em: 16 abr. 2018.

WAKELING, S.et al. Academic communities: the role of journals and open-access mega-journals in scholarly communication. Journal of Documentation, v. 75, n. 1, p. 120-139, 2019. 



\section{Diretórios de políticas editoriais sobre 0 acesso aberto}

Michelli Costa ${ }^{4}$

Larissa de Araujo Alves

s articulações em prol do movimento de acesso aberto às publicações científicas (MAA) foram sendo estabelecidas de maneira descentralizada e espontânea no final da década de 90 e início dos anos 2000. As declarações de acesso aberto constituem-se com importantes documentos balizadores do processo, que além de servirem de registros das problemáticas da comunicação científica e anseios dos pesquisadores, orientam para uma ação orquestrada em busca dos objetivos comuns. Neste sentido, destacam-se três declarações, internacionalmente reconhecidas como fundadoras do MAA, denominadas Budapest Open Access Initiative (BOAI), Declaração de Bethesda e Declaração de Berlim (BUDAPEST..., 2002; BETHESDA ...., 2003; BERLIN .... 2003).

4 Doutora em Ciência da Informação. Universidade de Brasília (UnB). michelli@unb.br

5 Estudante de Biblioteconomia. Universidade de Brasília (UnB). larisaraujoh@gmail.com 
A publicação da BOAI marcou oficialmente o apoio da comunidade científica na busca de alternativas em prol da disponibilização da literatura científica gratuitamente, online, em texto completo e em formato livre, de modo que os usuários da Internet tivessem a oportunidade de acessar, baixar, ler, copiar e utilizar o conteúdo dos trabalhos sem empecilhos legais ou de custos, desde que fossem sempre atribuídos os devidos créditos aos autores e/ou responsáveis intelectuais pelas publicações. Além de estabelecer um entendimento universal sobre o conceito de acesso aberto, a BOAl definiu duas estratégias de ação com o intuito de orientar o alcance dos objetivos do MAA, que são: os periódicos de acesso aberto e o autoarquivamento da literatura científica em repositórios digitais.

A Declaração de Bethesda, publicada em 2003, recebe destaque especial, visto que além de propor aos participantes da cadeia de produção editorial (autores, editores, agências de fomento e profissionais da informação) formas de atuação compatíveis com as ideias do MAA, estabelece duas condições primordiais para se considerar uma publicação como de acesso aberto. A primeira diz respeito aos direitos de uso, que devem ser os mais amplos possíveis. Tais direitos são comumente estabelecidos e registrados a partir das licenças de uso propostas pelo Creative Commons ${ }^{6}$. Enquanto a segunda condição trata do depósito imediato da publicação em pelo menos um repositório de acesso aberto.

Os repositórios de acesso aberto foram se consolidando a partir de duas naturezas. A primeira foi a institucional, onde as instituições de ensino superior e de pesquisa se comprometeram a disponibilizar em acesso aberto à produção científica de seus membros. A segunda, segue os

6 De acordo com dados disponibilizados pelo DOAJ em maio de 2019, 98\% (3923130) das licenças vinculadas aos periódicos cadastrados eram CC 
mesmos objetivos da primeira, mas delimita-se a partir de áreas temáticas e é gerido por associações científicas internacionais.

A proposta da criação de repositórios de acesso aberto fundamenta-se na responsabilidade que as instituições produtoras de conhecimento científico devem ter em disponibilizar seus resultados. No entanto, quando os resultados encontram-se publicados em artigos de periódicos, a disponibilização desse material precisa ser negociada com as instituições publicadoras, que via de regra, são as detentoras dos direitos de distribuição de cópias do material. Como forma de otimizar a comunicação das instituições publicadoras acerca das possibilidades de armazenamento e distribuição dos artigos publicados, foram criados diretórios de políticas editoriais sobre o acesso aberto.

Dentre os exemplos de diretórios de políticas editoriais existentes, destacam-se as experiências do Sherpa/RoMEO ${ }^{7}$, Dulcinea ${ }^{8}$ e Diadorim ${ }^{9}$. Todos esses serviços caracterizam-se como fontes confiáveis de informação que promovem a difusão e a divulgação de aspectos associados ao acesso, uso e fornecimento de conteúdos submetidos e publicados em periódicos que, determinadas vezes, não são claramente apresentados ou facilmente encontrados, por exemplo, nas páginas web das editoras. Desse modo, os diretórios em questão funcionam como ferramentas facilitadoras das atividades de disponibilização e interpretação das políticas editoriais de acesso e armazenamento de publicações, fato que contribui para: a) melhoria dos acordos firmados entre as partes envolvidas no processo de publicação de trabalhos científicos - autores, editores e gestores de repositórios digitais - e b) redução de problemas relacionados às concessões e usos indevidos de trabalhos publicados.

7 Disponivel em: <:http://www.sherpa.ac.uk/romeo/index.php>. Acesso em: 27 maio 2019.

8 Disponivel em:< https://www.accesoabierto.net/dulcinea/>. Acesso em: 27 maio 2019.

9 Disponível em: <http://diadorim.ibict.br/>. Acesso em: 27 maio 2019. 
Especialmente no que tange o acesso aberto, por meio do registro das políticas em diretórios como Sherpa/RoMEO, Dulcinea e Diadorim, as editoras e/ou instituições publicadoras têm a possibilidade explicitar o grau de concordância que adotam em relação ao MAA, em virtude da declaração feita sobre o tipo de acesso permitido pelo periódico (aberto, híbrido ou restrito).

Quanto à nomenclatura dos diretórios citados, a página web "About/sobre" do portal Dulcinea afirma que o nome atribuído ao diretório não se trata de um acrônimo (sigla) e foi pensado usando a mesma lógica da designação dada ao SHERPA/Romeo. Diante de tal informação, nota-se que Diadorim, Dulcinea e Romeo representam o nome de importantes personagens da literatura.

Posto isso, com o intuito de detalhar algumas características individuais dos diretórios Sherpa/RoMEO, Dulcinea e Diadorim, a seguir estão apresentados aspectos associados à nacionalidade, abrangência, categorias de permissão de arquivamento e tipos de acesso registrados em cada um desses serviços difusão de políticas editoriais.

\subsection{Sherpa/RoMEO}

Entendido como uma base de dados internacional de armazenamento de políticas de copyright e auto-arquivamento de instituições publicadoras de periódicos, o Sherpa/RoMEO foi criado como a parte do projeto Securing a Hybrid Environment for Research Preservation and Access (SHERPA) voltada para estudo da propriedade intelectual e dos direitos autorais (HUBBARD; SHERPA, 2003). Tal diretório registra e organiza políticas de editoras localizadas em todo mundo, mas com forte predominância das 
editoras relacionadas à Europa, Canadá, Estados Unidos da América e Austrália. As informações sobre as editoras são atualizadas por meio da colaboração efetiva da comunidade e de instituições parceiras do SHERPA/RoMEO. Já em relação a obtenção de informações associadas aos periódicos, essas provêm de serviços mantidos por instituições e/ ou iniciativas como a British Library, o Directory of Open Access Journals (DOAJ) e o Entrez, lista de revistas acessada por meio da National Center for Biotechnology Information (NCBI).

A organização e classificação dos tipos de políticas editoriais registradas no SHERPA/RoMEO é feita por meio de um sistema de código de cores. Cada tonalidade da escala de cores representa uma categoria de permissão de arquivamento das versões pré-print (antes da avaliação pelos pares) e pós-print (rascunho produzido após as melhorias sugeridas pelos avaliadores) das publicações dos periódicos cadastrados no diretório.

Quadro 6.1 - Classificação das políticas de arquivamento definidas pelo SHERPA/ ROMEO.

\begin{tabular}{|c|l|}
\hline Cores RoMEO & \multicolumn{1}{c|}{ Politica de arquivo } \\
\hline Verde & Permite arquivar a versão pré-print e pós-print ou versão/PDF do editor \\
\hline Azul & $\begin{array}{l}\text { Permite arquivar a versão pós-print (rascunho final após revisão pelos pares) ou versão /PDF do } \\
\text { editor }\end{array}$ \\
\hline Amarelo & Permite arquivar apenas a versão pré-print (antes da avaliação pelos pares) \\
\hline Branco & Não há permissão formal para arquivamento de nenhuma versão da publicação \\
\hline
\end{tabular}

Fonte: SHERPA/RoMEO, traduzido e adaptado.

O código de cores supramencionado tornou-se um padrão no contexto dos diretórios de políticas editoriais e foi incorporado tanto ao Dulcinea quanto ao Diadorim para organização das informações disponibilizadas sobre possibilidades de arquivamento em repositórios digitais de acesso aberto. 


\subsection{Dulcinea}

Apesar do Sherpa/RoMEO abranger políticas editoriais de vários países do mundo, percebe-se a predominância de alguns países nas políticas cadastradas. Com vistas a ampliar a participação de outros editores científicos, diversos países criaram diretórios nacionais de políticas editoriais. No contexto espanhol, o diretório de políticas editoriais existente é o Dulcinea, o qual caracteriza-se como produto desenvolvido no interior do projeto El accesoabierto a la producción científica en España: análisis de la situación actual y presentación de políticas y estrategias para promover su desarrollo, o qual foi coordenado pelo Ministério da Educação e Ciência da Espanha e financiado pelo Plan Nacional de I+ D+I (DULCINEA, [201-?].

O diretório Dulcineia foi criado com a finalidade de: deixar claro aos autores questões relacionadas às condições de submissão de artigos aos periódicos científicos; disponibilizar informações que auxiliassem o trabalho dos gestores de repositórios digitais de acesso aberto; minimizar problemas entre editores, autores e repositórios digitais por meio do estabelecimento de boas práticas de definição de políticas de copyright forneçam entendimento claro sobre as possibilidades de uso e reuso de publicações presentes em revistas científicas. Vale destacar que esses aspectos defendidos pelo diretório espanhol também são aplicáveis aos outros serviços de difusão de políticas editoriais mencionados neste trabalho. 


\subsection{Diadorim}

Seguindo a tendência internacional e com o objetivo de ampliar a discussão acerca do acesso aberto no Brasil, promover o entendimento das políticas editoriais sobre o acesso aberto de periódicos brasileiros e promover o povoamento dos repositórios institucionais e temáticos, foi criado o Diadorim. O Diretório de Políticas Editoriais das Revistas Científicas Brasileiras, também conhecido como Diadorim, surgiu sob a responsabilidade do Instituto Brasileiro de Informação em Ciência e Tecnologia (IBICT), com subsídios financeiros provenientes da Financiadora de Estudos e Projetos (FINEP).

O registro das políticas editoriais dos periódicos científicos brasileiros no Diadorim é uma responsabilidade das editoras. Essas podem efetuar o cadastramento de suas publicações no diretório por meio do preenchimento de um formulário online composto por 14 questões, que abordam: informações de identificação da revista (título, ISSN, URL, editora, meio da publicação, área do conhecimento); contatos da revista (e-mail, telefone); permissões de armazenamento, tipo de acesso definido pela editora e tempo de embargo da revista.

Outro aspecto importante é que o Diadorim categoriza os tipos de acesso das publicações a serem armazenadas nos repositórios digitais como: aberto, aberto após determinado período de embargo, restrito. O primeiro tipo refere-se às revistas que coadunam completamente com a via verde do MAA e permitem a disponibilização do conteúdo que publicam em texto completo e online. O acesso após período de embargo, definido pela instituição publicadora, diz respeito a liberação do conteúdo dos artigos de revista para consulta e uso após determinado tempo, contado a partir da data de publicação oficial. E, o terceiro tipo proíbe que o texto completo da publicação fique acessível gratuitamente. 


\subsection{Considerações finais}

O acesso aberto é um fenômeno contemporâneo da comunicação científica irreversível e com diversos desdobramentos na cultura acadêmica. É urgente que os editores científicos considerem as demandas do MAA e estejam aptos a dialogar com elas. Os diretórios de políticas editoriais aqui citados foram criados com a finalidade de promover o entendimento do posicionamento dos editores científicos acerca das prerrogativas do acesso aberto e contribuir com a divulgação dos periódicos. Portanto, apresentam-se como importantes instrumentos para estabelecer ou registrar a política editorial dos periódicos no que diz respeito ao acesso aberto. Com isso, promove-se condições para que as políticas editoriais sejam conhecidas e respeitadas.

Os diretórios de política editorial sobre o acesso aberto também são fontes de informação relevantes para os autores, suas instituições e agência de fomento à pesquisa. Em diversas regiões como a União Européia e América do Norte, a exigência para divulgação dos resultados de pesquisas financiadas é uma forte tendência. Em todos esses contextos, os diretórios de políticas editoriais sobre o acesso aberto cumprem a necessária missão de sistematizar e comunicar informações pertinentes sobre os periódicos científicos. 


\section{Referências}

BERLIN DECLARATION ON OPEN ACCESS TO KNOWLEDGE IN THE SCIENCES AND HUMANITIES. 2003. Disponível em: <https://openaccess.mpg.de/Berlin-Declaration>. Acesso em: 19 ago. 2019.

BETHESDA STATEMENT ON OPEN ACCESS PUBLISHING. 2003. Disponível em: <http://legacy.ear/ham.edu/ peters/fos/bethesda.htm>. Acesso em: 19 ago. 2019.

BUDAPEST OPEN ACCESS INITIATIVE. fev, 2002. Disponível em: < http:// www.budapestopenaccessinitiative.org/read >. Acesso em: 19 ago. 2019.

DULCINEA. Acerca. [201-?]. Disponível em: https://www.accesoabierto. net/dulcinea/acerca. Acesso em: 29 maio 2018.

HUBBARD, B. SHERPA and Institutional Repositories. Serials, v. 16, n. 3, p. 243-247, 2003. Disponível em: http://eprints.nottingham.ac.uk/95/1/ sherpa\%26instrep.pdf. Acesso em: 27 maio 2019.

MELERO, R. et al. Dulcinea: iniciativa para el análisis de los derechos de copyright y autoarchivo de revistas científicas españolas. In INTERINFORMACIÓN: XI JORNADAS ESPAÑOLAS DE DOCUMENTACIÓN, 11, 2009, Zaragoza. Proceeding... .Zaragoza: Jornadas Españolas De Documentación , 2009, p. 117-122 



\section{Comunicação na ciência aberta: depósito e disseminação de dados}

Ingrid Schiessl

Janinne Barcelos

a história da ciência ocidental, o processo de institucionalização da atividade científica está intrinsecamente relacionado ao fluxo, circulação e negociação de ideias e ideais entre atuantes internos e externos ao contexto e ambiente de produção da ciência e tecnologia. A curiosidade de entender o mundo ao redor, passou de especulações e experimentos caseiros para argumentações metódicas e grandes pesquisas em laboratórios. De investimento de um homem só, em séculos de transformação, a produção do conhecimento científico passou a ser o comprometimento de colégios invisíveis, de comunidades e um convite à participação de toda a sociedade especializada.

Como explica Burkett (1990) um trabalho não é ciência até que seja revisto por outros cientistas. Além de desenvolver os estudos, é necessário que o cientista comunique os resultados - de forma oral ou escrita - para que possam ser avaliados por seus pares que, por sua vez, vão 
publicar suas impressões sobre esse estudo, compondo um sistema de constante revisão e renovação das informações científicas. Este sistema de comunicação é, justamente, o que mantém os pesquisadores em constante produção e desenvolvimento.

Tal sistema, no entanto, deve ser compreendido de acordo com a ciência, a dinâmica social dos cientistas e a sociedade de cada época. No século XVI, por exemplo, quando pesquisadores ainda se encontravam às escondidas para evitar repressões do Estado e da igreja, a comunicação dos resultados acontecia através de cartas postadas como correspondência pessoal, na tentativa de manobrar a censura. Os assuntos discutidos durante as reuniões eram registrados em atas e serviam de fonte de consulta apenas para os sócios das academias de ciência. Mais tarde, esse material impresso (cartas e atas) teria dado origem aos primeiros periódicos científicos (MUELLER; CARIBÉ, 2010).

Depois da inovação de Gutenberg a comunicação da ciência ganhou novas vozes (OLIVEIRA, 2002). O livro científico impresso passou a fazer parte do cenário europeu e as informações tornaram-se disponíveis para um público mais largo que o de cientistas. Como por exemplo o Fascículo de Medicina, de 1491, publicado em diferentes idiomas, que trazia significativas informações da anatomia masculina e feminina para públicos variados como estudantes e aprendizes de cirurgiões, entre outros. Também disposto a tornar suas obras acessíveis para todo público que tivesse interesse na ciência, Galileu Galilei passou a usar o italiano nas publicações de seus estudos, ao invés do latim (NAESS, 2015). Na obra Mensageiro Celeste, de 1610, o astrônomo relatou em língua vernácula sua descoberta e observações das três luas de Júpiter.

Entre outros exemplos de sucessos editoriais, dessa mesma época, também podemos citar: Secreti de Alessio Piemontese que teve cerca de 80 edições em várias línguas (italiano, francês, alemão, inglês, latim, 
flamengo, espanhol, polonês e dinamarquês) e; Silva de varia lección, de Pedro Mexia, que dentro de um século, ganhou 107 edições (em espanhol, francês, italiano, inglês, flamengo e alemão). Além das traduções, a história da Comunicação Científica revela outras iniciativas como a publicação do periódico londrino Philosophical Transactions, produzido em pelo alemão, Henry Oldenburg, considerado o marco inicial do jornalismo científico no mundo (BURKETT, 1990).

Décadas depois, as tecnologias digitais de informação e comunicação, especialmente a Web, causaram mudanças significativas no cenário das publicações científicas. As dinâmicas de transmissão de informação e de publicação se transformaram e, não obstante, o fluxo da comunicação científica também passou a ser realizado no espaço virtual sem as imposições temporais e geográficas. Os crescentes avanços da Internet, ampliaram os processos de descentralização e disseminação do conhecimento científico. Por sua vez, a forma de produzir ciência também mudou.

Em 2003, a Declaração de Berlim sobre Acesso Aberto ao Conhecimento em Ciências e Humanidades apresenta e discute sobre o novo contexto do movimento de acesso livre, o qual estabelece que o acesso aberto é a fonte de conhecimento humano e patrimônio cultural validada pela comunidade científica. Desta forma, os resultados de pesquisas científicas ganham novas formas e formatos, são os dados brutos e metadados, as fontes originais, as representações digitais de materiais pictóricos e gráficos, além do material acadêmico multimídia.

Se no modelo tradicional de comunicação da ciência o compartilhamento de informação é imprescindivel, o ato de compartilhar os resultados de pesquisa também incide diretamente em seu progresso (MUELLER, 2005). Esta mesma lógica se aplicaria na ciência aberta, já que qualquer mudança nas pesquisas implica nos processos intermediários. 
Em muitos casos, os dados de pesquisas são coletados, armazenados e processados na forma digital. As instituições têm criado repositórios, alinhados ao Movimento de Acesso Aberto, para disponibilizar os resultados de pesquisa em forma de artigos, livros e outros, mas nem sempre possuem os dados de pesquisa em seus acervos.

A falta de informações sobre o valor dos dados de pesquisa é um dos obstáculos que impedem o avanço no processo de disponibilização. Pois, alguns dados são sensíveis como, por exemplo, informações confidenciais de pacientes ou estratégias que não devem ser publicadas imediatamente. Todavia, a comunidade científica apoia o compartilhamento de dados científicos, porque todos entendem que os dados são indispensáveis ao pesquisar e desenvolver métodos de estudo, técnicas de análise e implementações de software (PIWOWAR, 2013)

Compartilhar dados de pesquisa com outros pesquisadores permite que esses recursos valiosos possam contribuir para além do seu propósito original. Além do mais, os dados de pesquisa podem ser usados para confirmar os resultados do estudo e os dados brutos podem ser explorados para se confirmar novas hipóteses, principalmente, quando esses podem ser combinados com outros conjuntos de dados de pesquisa. Como defendem Piwowar e Vision (2013), a comunidade científica também se beneficia do compartilhamento dos dados, pois, ajuda a identificar erros, desestimula fraudes, é útil para treinar novos pesquisadores e aumenta o uso eficiente de recursos financeiros e de população de pacientes, evitando a coleta duplicada de dados.

Sabe-se que há desafios e custos para compartilhar os dados de pesquisa. Alguns deles são de responsabilidade das instituições, como por exemplo, os repositórios de dados, o quais devem ser criados e gerenciados pela mesma. O ônus para os pesquisadores é documentar, formatar e disponibilizar os dados, o que demanda tempo e conhecimento em 
ferramentas de gestão. Contudo, importa ressaltar que o compartilhamento dos dados pode impactar diretamente no aumento do número de citações do pesquisador que os compartilha (TENOPIR et al., 2011). A literatura apresenta evidências de que estudos que disponibilizam seus dados realmente recebem mais citações daqueles que não compartiIham (GLEDITSCH; METELITS; STRAND, 2003; PIWOWAR, DAY; FRIDSMA, 2007; IOANNIDIS et al., 2009; PIENTA; ALTER; LYLE, 2010; HENNEKEN; ACCOMAZZI, 2011; SEARS, 2011; DORCH, 2012).

Outro desafio está na especificidade de cada área. Uma pesquisa da editora científica Wiley apontou que o compartilhamento de dados pelos pesquisadores é diferente em cada disciplina acadêmica. De acordo com a pesquisa, $66 \%$ dos cientistas da saúde e da biologia compartilham seus dados com outros pesquisadores, principalmente em repositórios de dados ou em periódicos de dados. Enquanto apenas 36\% dos cientistas sociais e de humanidades compartilham seus dados, muitas vezes informalmente, ou seja, dentro de sua própria equipe ou instituição de pesquisa (FERGUNSON, 2014, tradução nossa). Tal comportamento, pode resultar em campos de pesquisa que nunca atingem seu potencial máximo, seja porque os pesquisadores repetem desnecessariamente o trabalho uns dos outros ou porque as oportunidades de pesquisa não são exploradas.

Importa salientar, ainda, a falta de políticas específicas para o depósito e compartilhamento de dados nos periódicos. Nota-se, que um número crescente de periódicos tem exigido que os artigos publicados sejam acompanhados pelos dados de pesquisa. Ou seja, há um forte apelo para o compartilhamento de dados como boa estratégia para o contínuo progresso da ciência, mas este não vem acompanhado de políticas que estabelecem quais, quando e como os dados devem ser compartilhados. 
De fato a ciência está caminhando para uma maior abertura, não apenas das publicações de resultados, mas também dos códigos de software, métodos experimentais e dados de pesquisa. Porém faz-se necessário maior reflexão, por parte da academia e das editoras, sobre questões espinhosas como: ética no compartilhamento de dados; concorrência entre os pares; tempo gasto na disponibilização desses conjuntos de dados; falta de especialização necessária em curadoria de dados e metadados; custos de armazenamento; políticas claras sobre como, onde e quando compartilhá-los e; particularidades de cada área. (GEWIN, 2016).

Este é o momento para que editores e pesquisadores se envolvam ativamente e resolvam essas questões. Em primeiro lugar, para garantir que os futuros ditames políticos não sejam insensíveis às necessidades e à natureza epistemológica de cada campo. Depois, para promover abordagens éticas, metodologicamente sólidas e criativas para o armazenamento e o compartilhamento de dados. A definição destas práticas vai traçar novos caminhos para a pesquisa em ciência aberta e, quem sabe, permitir que ela realmente atinja um público mais amplo, aumentando assim o impacto e alcance dos trabalhos.

\section{Referências}

BURKETT, W. Jornalismo Científico: como escrever sobre ciência, medicina, e alta tecnologia para os meios de comunicação. Rio de Janeiro: Forense Universitária, 1990.

CAVALCANTI, M. T.; SALES, L. F. Gestão de dados de pesquisa: um panorama da atuação da União Europeia. Biblos, v. 31, n. 1, p. 73-98, 2017. 
$\mathrm{DORCH}, \mathrm{B}$. On the Citation Advantage of linking to data: Astrophysics. Hprints \& Humanities [Repositório]. Disponível em: <https://hal-hprints. archives-ouvertes.fr/hprints-00714715>. Acesso em: 19 ago. 2019.

FERGUNSON, L. How and Why Researchers Share Data (and Why They don't). The Wiley Network (website). Disponível em: <https://www.wiley. com/network/researchers/licensing-and-open-access/how-and-why-researchers-share-data-and-why-they-dont>. Acesso em: 19 ago. 2019.

GEWIN, V. Data sharing: An open mind on open data. Nature, v. 529, n. 7584, 7 jan 2016.

GLEDITSCH, N. P.; METELITS, C.; STRAND, H. Posting your data: will you be scooped or will you be famous. International Studies Perspectives, v. 4, n. 1, p. 89-97, 2003.

HENNEKEN, E. A.; ACCOMAZZI, A. Linking to Data : effect on Citation Rates in Astronomy. CoRR, v. abs/1111.3618, 2011.

IOANNIDIS, J. P. A. et al. Repeatability of published microarray gene expression analyses. Nature Genetics, v. 41, p. 149, 28 jan. 2009.

KUM, H.-C.; AHALT, S.; CARSEY, T. M. Dealing with Data: Governments Records. Science, v. 332, n. 6035, p. 1263-1263, 10 jun. 2011.

MUELLER, S. P. M.; A publicação da ciência: áreas científicas e seus canais preferenciais. DataGramaZero, v. 6, n. 1, fev. 2005. Artigo02. Disponível em: <https://doi.org/10.7717/peerj.175>. Acesso em: 19 ago. 2019.

MUELLER, S. P. M.; CARIBE, R. de C. do V. Comunicação científica para o público leigo: Inf. Inf., Londrina, v. 15, n. esp, p. 13 - 30, 2010. Disponível 
em: < http://repositorio.unb.br/bitstream/10482/13202/1/ARTIGO_ComunicacaoCientificaPublico.pdf >. Acesso em: 04 fev. 2014.

NAESS, Atle. Galileu Galilei: um revolucionário e seu tempo. Rio de Janeiro: Zahar, 2015.

OLIVEIRA, F. D. Jornalismo Científico. São Paulo: Contexto, 2002.

PIENTA, A. M.; ALTER, G. C.; LYLE, J. A. The Enduring Value of Social Science Research: The Use and Reuse of Primary Research Data. DeepBlue, 2010. Disponível em: <http://hdl.handle.net/2027.42/78307> .

PIWOWAR, H. A.; DAY, R. S.; FRIDSMA, D. B. Sharing Detailed Research Data Is Associated with Increased Citation Rate. PLOS ONE, v. 2, n. 3, p. e308, 21 mar. 2007.

PIWOWAR, H. A.; VISION, T. J. Data reuse and the open data citation advantage. PeerJ, v. 1, p. e175, 1 out. 2013.

SEARS, J. Data Sharing Effect on Article Citation Rate in Paleoceanography. 2011. AGU Fall Meeting Abstracts, p. 1628, 1 dez. 2011.

SILVA, M. A. B.; RIBEIRO, F. Das "Ciências" Documentais à Ciência da Informação: ensaio epistemológico para um novo modelo curricular. Porto: Afrontamento, 2002

TENOPIR, C. et al. Data sharing by scientists: practices and perceptions. PLoS ONE, v. 6, n. 6, e21101, jun. 2011. Disponível em: <https://doi. org/10.1371/journal. pone.0021101 > Acesso em 18 maio 2018.

COMO CITAR: SCHIESSL, Ingrid T; BARCELOS, Janinne. Comunicação na ciência aberta: depósito e disseminação de dados. In: SHINTAKU, Milton; SALES, Luana Farias (Orgs.) Ciência aberta para editores científicos. Botucatu, SP. ABEC, 2019. p. 51-58. DOl: http://dx.doi.org/10.21452/978-85-93910-02-9.cap7 


\section{A revisão por pares}

\section{no contexto da Ciência}

\section{Aberta: uma breve}

apresentação

Janaynne Carvalho do Amaral ${ }^{10}$

Eloísa Príncipe ${ }^{11}$

astrônomo e cientista da informação britânico Jack Meadows (19342016), no prefácio da sua obra clássica A comunicação científica (1999), afırma: "A comunicação situa-se no próprio coração da ciência. É para ela tão vital quanto a própria pesquisa, pois a esta não cabe reivindicar como legitimidade este nome enquanto não houver sido analisada e aceita pelos pares". E quem são, afınal de contas, os pares? Os pares, também denominados de avaliadores, revisores, pareceristas ou árbitros, são pesquisadores atuantes na mesma área de pesquisa de um autor e que avaliam o mérito científico de artigos submetidos à publicação.

10 menequete@gmail.com (https://orcid.org/0000-0002-9817-4572)

11 principe@ibict.br (https://orcid.org/0000-0002-1540-0854) 
Já o termo "revisão por pares", vem da sua tradução do inglês ao português, peer (pares) review (revisão), o que muitas vezes gera mal-entendidos, uma vez que a palavra revisão, na língua portuguesa, remete ao revisor de texto profissional responsável pelas correções gramaticais, ortográficas e de pontuação em um texto.

A revisão por pares, também chamada de arbitragem ou avaliação por pares é, conforme Bornmann (2013), a principal ferramenta de controle de qualidade das publicações na maioria das áreas do conhecimento; e ao avaliar a qualidade da pesquisa, ela também designa qual pesquisa científica deve receber financiamento e quais resultados de pesquisa deverão ser publicados. Nassi-Calò (2015, on-line) complementa que o processo é "[...] a etapa mais importante do processo de publicação de resultados de pesquisa na opinião de todos os atores da cadeia editorial, como a que confere qualidade, confiabilidade e originalidade ao artigo. E ainda, de acordo com Coimbra Júnior (2003, p. 66), o processo envolve:

[...] o emprego sistemático de peers (ou colegas), na assessoria aos editores das revistas na seleção dos artigos. A expectativa é de que esse sistema seja suficientemente sensível para detectar aqueles trabalhos realmente originais, com metodologias e análises capazes de, efetivamente, somarem-se aos conhecimentos acumulados em um determinado campo da ciência. Espera-se ainda que os revisores sejam capazes de apontar erros, omissões, além de eventuais conflitos de interesse e desvios da ética.

Trezentos e cinquenta quatro anos de idade tem o processo de revisão por pares, se consideramos o seu nascimento em 1665, ano em que surgiram os primeiros periódicos científicos - o Journal des Savants, na França; Philosophical Transactions of the Royal Society, em Londres - e o ano de publicação deste texto. Isso porque, segundo a Royal Society 
(2012), quando Henry Oldenburg, o primeiro editor do periódico britânico, iniciou o processo de revisão por pares convidando três especialistas para avaliar um trabalho antes de decidir sobre a sua publicação.

Dentro do modelo tradicional de revisão por pares, as avaliações podem ser simples-cega (single-blind) - quando os revisores sabem quem são os autores, mas os autores desconhecem quem são os revisores; e duplo-cega (double-blind), quando ambos não conhecem a identidade um do outro. Tradicionalmente, os revisores são escolhidos pelo editor dentro da área temática do artigo, mas há periódicos que solicitam que os autores indiquem os avaliadores.

Entretanto, embora internacionalmente aceito, o sistema tradicional de revisão por pares possui os seguintes problemas: falta de confiabilidade e inconsistência; atraso e alto custo; falta de transparência; vieses sociais de publicação, com base no gênero, afiliação institucional e língua; falta de incentivo, ou seja, atividade sem remuneração e sem reconhecimento (ROSS-HELLAEUR, 2017); não detecta fraude e plágio (FRESCO-SANTALLA; HERNÁNDEZ-PÉREZ, 2014). Acrescenta-se também como desafio a esse processo o treinamento e a capacitação contínua dos pareceristas. Nesse cenário, toma impulso a revisão por pares aberta, um dos pilares da Ciência Aberta juntamente com o acesso aberto e os dados abertos (SPINAK, 2018). Albalgi, Clinio e Raychtock (2014, p. 435), explicam que a Ciência Aberta

[...] é hoje um termo guarda-chuva, que engloba diferentes significados, tipos de práticas e iniciativas, bem como envolve distintas perspectivas, pressupostos e implicações. Aí estão incluídas desde a disponibilização gratuita dos resultados da pesquisa (acesso aberto), até a valorização e a participação direta de não cientistas e não especialistas no fazer ciência, tais como "leigos" e "amadores" (ciência cidadã). 
Com base em uma revisão sistemática dos termos "Revisão por pares aberta" ou "revisão aberta", Ross-Hellaeur (2017) propõe que a revisão por pares aberta é um termo que engloba diversos modelos de revisão por pares alinhados com o espírito da Ciência Aberta. Segundo o autor, são características desse modelo de avaliação:

Identidades abertas: Autores e revisores sabem da identidade um do outro.

Pareceres abertos: Os pareceres são publicados juntamente com os artigos.

- Participação aberta: A comunidade em geral pode contribuir no processo de revisão por pares.

- Interação aberta: A discussão direta e recíproca entre autores e revisores é permitida e encorajada.

Abrir os manuscritos previamente à revisão: Os manuscritos são imediatamente disponibilizados (por exemplo, por meio de servidores preprint como arXiv) antes de qualquer procedimento formal de revisão por pares.

- Abrir comentários para versão final: revisar ou comentar as versões fınais de uma publicação.

- Plataformas abertas: A revisão por pares é dissociada do periódico e é facilitada por uma entidade organizacional. (ROSS-HELLAEUR, 2017, p. 11, tradução nossa).

De acordo com Ross-Hellaeur (2017), no que refere às Identidades abertas, o principal motivo para manter a anonimato do autor é evitar vieses 
de publicação como gênero, autores de instituições de prestígio e autores não nativos da língua inglesa. Por outro lado, o anonimato do revisor é protegido para evitar influência indevida, permitindo que ele possa avaliar o artigo de forma sincera sem correr o risco de sofrer retaliação por parte do autor. Contudo, o autor diz que abrir as identidades pode aperfeiçoar a qualidade da revisão, uma vez que os pareceristas terão mais receio de terem os seus nomes associados à pareceres mal elaborados.

Os Pareceres abertos consistem na proposta de publicar as avaliações feitas pelos pareceristas juntamente com o artigo. Entre as vantagens de publicar pareceres estão o potencial de reuso de informações atualmente restritas ao editor, a promoção da transparência e da qualidade das avaliações e maior visibilidade da atividade de revisão por pares. (ROSS-HELLAEUR, 2017).

Na Participação aberta, os membros da comunidade científica podem participar da revisão por pares tanto contribuindo com pareceres mais completos quanto com textos mais curtos (ROSS-HELLAEUR, 2017). Citando Ware (2011), Ross-Hellaeur complementa que pessoas externas à comunidade científica também podem participar, como representantes da indústria ou membros de grupos específicos, como, por exemplo, no que se refere às revistas médicas, os pacientes.

Quanto à Interação aberta, que encoraja o diálogo direto entre pareceristas e autores, corremos o mesmo risco indicado na característica Identidade aberta, ou seja, o desentendimento entre pareceristas e autores. Pesquisas anteriores à revisão por pares aberta, sugerem que, principalmente nos casos de uma avaliação negativa, os autores gostariam de contestá-la para o editor. (WELLER, 2001). 
Abrir os manuscritos previamente à revisão significa a publicação prévia em servidores de preprints, como arXiv.org ${ }^{12}$ e bioRxiv.org ${ }^{13}$ como forma de tornar os seus manuscritos disponíveis para todos (ROSS-HELLAEUR, 2017). Ele sugere que essa característica beneficia o autor na medida em que ele pode garantir a sua prioridade ao relatar descobertas, ao invés de esperar o longo processo de avaliação e publicação do periódico. Para Pöschl (2012 apud ROSS-HELLAEUR, 2017), publicar o artigo antes da revisão por pares também contribuiu para a sua melhoria. Para Ross-Hellaeur (2017), nessa característica os comentários deixados no artigo por revisores ou o público em geral permite que os leitores acompanhem a revisão por pares em tempo real.

Abrir comentários para a versão final pode soar incoerente se enxergamos a revisão por pares como o processo final da avaliação de um resultado de pesquisa, uma vez que a ciência está em constante processo de mudança e melhoria. (ROSS-HELLAEUR, 2017).

Nas Plataformas abertas, a revisão por pares é dinamizada por serviços como a RUBRIQ ${ }^{14}$ e a Peerage of Science ${ }^{15}$ (ROSS-HELLAEUR, 2017). Nelas, os autores são convidados a submeterem os seus manuscritos para serem avaliados antes da submissão a um periódico.

As características da revisão por pares aberta apresentadas trazem possíveis soluções para os desafios enfrentados pelo modelo tradicional de revisão por pares, contudo, embora se reconheça os seus benefícios e contribuições, há um longo caminho a ser percorrido tanto no campo

12 Disponivel em: https://arxiv.org/. Acesso em: 6 jun. 2019.

13 Disponivel em: https://www.biorxiv.org/. Acesso em: 6 jun. 2019.

14 Disponivel em: https://www.researchsquare.com/company/publishers/rubriq. Acesso em: 6 jun. 2019.

15 Disponivel em: https://www.peerageofscience.org/. Acesso em: 06 jun. 2019. 
teórico quanto prático para melhor compreendê-la e adotá-la. Atualmente, o modelo de avaliação mais presente no Brasil e no exterior é o tradicional, mas, possivelmente ambos serão adotados paralelamente, e por muito tempo, pela comunidade científica.

\section{Referências}

ALBAGLI, S.; CLINIO, A.; RAYCHTOCK, S. Ciência aberta: correntes interpretativas e tipos de ação. Liinc em Revista, Rio de Janeiro, v.10, n.2, p. 434-450, nov. 2014. Disponível em: http://www. ibict.br/liinc. Acesso em: 19 jan. 2018.

BORNMANN, L. Scientific peer review. Annual Review of Information Science and Technology, v. 45, n. 1, p. 197-245, Jan. 2013. Disponível em: https://onlinelibrary.wiley.com/doi/abs/10.1002/aris.2011.1440450112. Acesso em: 22 abr. 2018.

COIMBRA JÚNIOR, C. E. A. Desafios à avaliação da literatura científica: a revisão pelos pares. Cadernos de Saúde Pública, v. 19, n. 5, p. 12241225, 2003. Disponível em: http://www.scielo.br/scielo.php?script=sci_arttext\&pid=S0102-311 X2003000500001 \&lng=pt\& $n r m=i s o \& t \mid n g=p t$. Acesso em: 20 maio 2019.

FRESCO-SANTALLA, A.; HERNÁNDEZ-PÉREZ, T. Current and evolving models of peer review. The Serials Librarian, v. 67, n. 4, p.373-398, 2014. Disponível em: https://www.tandfonline.com/doi/abs/10.1080/036152 6X.2014.985415. Acesso em: 22 abr. 2018.

MEADOWS, A. J. A comunicação científica. Tradução Antonio Briquet de Lemos. Brasília, DF: Briquet de Lemos, Livros, 1999. 
NASSI-CALÒ, L. A revisão por pares como objeto de estudo. SciELO em Perspectiva, 2015. Disponível em: http://blog.scielo.org/blog/2015/04/24/a-revisao-por-pares-como-objeto-de-estudo/. Acesso em: 13 ago. 2018.

ROSS-HELLAUER, T. What is open peer review? A systematic review. F1000Research, v. 6, 588, 2017. Disponível em: https://f1000research. com/articles/6-588/v1. Acesso em: 22 abr. 2018.

ROSS-HELLAUER, T.; DEPPE, A.; SCHMIDT, B. Survey on open peer review: attitudes and experience amongst editors, authors and reviewers. PLoS ONE [online], v.12, n. 12, 2017. Disponível em: http://journals. plos.org/plosone/article?id=10.1371/journal. pone.0189311. Acesso em: 22 abr. 2018.

SPINAK, E. Sobre as vinte e duas definições de revisão por pares aberta... e mais. SciELO em Perspectiva, São Paulo, fev. 2018. Disponível em: http://blog.scielo.org/blog/2018/02/28/sobre-as-vinte-e-duas-definicoes-de-revisao-por-pares-aberta-e-mais/\#.WtzylMgvzIU. Acesso em: 22 abr. 2019.

THE ROYAL SOCIETY. Science as an open enterprise. London: The Royal Society Science Policy Centre, 2012. Disponível em: https://royalsociety. org/ /media/policy/projects/sape/2012-06-20-saoe.pdf. Acesso em: 21 abr. 2018.

WELLER, A. C. Editorial Peer Review: its strengths and weaknesses. Medford, NJ: Information Today, 2001. (ASIS\&T Monograph Series). 342 p. 


\section{0 caderno aberto de laboratório de}

Jean-Claude Bradley

Anne Clinio ${ }^{16}$

caderno aberto de laboratório (open notebook science em inglês) é uma proposta elaborada por Jean-Claude Bradley, professor e pesquisador de Química na Universidade de Drexel University, como "uma maneira de fazer ciência na qual - da melhor maneira possível - você torna toda a sua pesquisa livre e acessível ao público em tempo real" (BRADLEY, 2010). Segundo o autor, esta expressão se refere à:

existência de uma URL linkada a um caderno de laboratório (como este) que está disponível abertamente e é indexado por ferramentas de busca habituais. Ele não precisa obrigatoriamente parecer com um caderno de laboratório de papel,

16 Doutora e Mestre em Ciência da Informação pelo Programa de Pós-Graduação em Ciência da Informação, convênio Ibict-UFRJ. Membro do Laboratório Interdisciplinar sobre Informação e Conhecimento (Liinc) (http://www.liinc.ibict.br). integrante da equipe da Vice Presidência de Ensino, Informação e Comunicação (VPEIC) da Fundação Oswaldo Cruz, membro do Grupo de Pesquisa em Ciência Aberta da Fiocruz (GTCA). Orcid: https://orcid.org/0000-0002-9702-859X 
mas é essencial que as informações necessárias para que o pesquisador chegue às suas conclusões estejam igualmente disponíveis para o resto do mundo. Basicamente, nenhuma informação privilegiada. (BRADLEY, 2006)

Sua origem se situa entre as críticas sobre os modos de produção e comunicação do conhecimento científico e a identificação de oportunidades pela confluência de novas formas de colaboração em ambientes digitais e a cultura digital livre. Segundo Bradley, o modo dominante de comunicação formal do conhecimento científico, baseado majoritariamente na publicação de artigos em revistas com sistema de avaliação às cegas por pares, afeta negativamente a pesquisa, este padrão fomenta uma cultura do segredo entre pesquisadores, desestimula a colaboração e promove informação de qualidade duvidosa, ao mesmo tempo que elimina informação relevante, desperdiça recursos financeiros e humanos, gera retrabalho e retarda o desenvolvimento científico.

Se, no passado, este era o único mecanismo possível para resguardar, em alguma medida, a qualidade das contribuições, a internet é considerada uma oportunidade tecnológica para eliminar a mediação da comunicação do conhecimento científico por um grupo muito pequeno de gatekeepers (editores, avaliadores e autores) que definem temas prioritários, formatos, critérios de cientificidade e qualidade, enfim, o que é publicável em revistas científicas. Tais gatekeepers reduzem drasticamente, segundo a avaliação de Bradley, tanto a quantidade como a qualidade da informação relevante circulante. Do ponto de vista quantitativo, o pesquisador estima que $87 \%$ da sua produção não ultrapassava os muros do laboratório porque são experimentos que não alcançam os "resultados esperados" e, portanto, são considerados irrelevantes para publicação. Já no aspecto qualitativo, ele identifica que a maioria dos artigos da sua área oferece descrições altamente condensadas, genéricas e insuficientes para sua reprodução por um cientista relativamente competente. 
Na contramão das práticas estabelecidas, o caderno aberto de laboratório proposto por Jean-Claude Bradley preconiza o compartilhamento, em tempo real, de todos os experimentos realizados em um laboratório, seja qual for o seu status (em andamento, finalizado, abandonado) ou resultado (favorável, desfavorável, contraditório ou ambíguo) em tempo real ${ }^{17}$. Isto porque, compartilhar os estágios intermediários, incertezas e dificuldades da pesquisa é considerada a melhor estratégia para atrair colaboradores e recursos e promover uma "ciência mais rápida, ciência melhor" (faster science, better science). A abertura também potencializa as oportunidades de escrutínio, validação, correção, refutação, complementação e aprendizagem por audiência mais ampla.

Na prática, o caderno aberto de laboratório de Bradley se baseia em uma "página de experimento", com formato estruturado, cujo preenchimento se torna obrigatório visa garantir a qualidade do registro e possibilitar sua reutilização em serviços de informação. Ela é composta por nove seções (número do experimento; representação gráfica do experimento, nome do pesquisador; objetivo; procedimento; resultado; discussão; conclusão e log) sendo o log a mais importante por registrar (de maneira independente, por terceiros) a marca temporal (third party timestamp) de quem fez uma contribuição, quando, onde, como e os resultados obtidos.

A entrada de informações adota um estilo objetivo, sem floreios, no qual o pesquisador deve relatar os procedimentos e os resultados parciais de cada etapa do experimento. Este formato dispensa a elaboração de uma narrativa, exigida nos artigos científicos, e constrói o "experimento sem história" (storyless experiment), que valoriza os resultados parciais (result-centric) em contraposição às revistas científicas que privilegiam a comunicação de experimentos (experiment-centric) ou a obtenção

17 Esta opção corresponde ao grau máximo de abertura. 0 autor também prevê outros três niveis de abertura. 
de uma molécula (molecule-centric). Algumas vantagens desta inovação são garantir maior precisão e riqueza de detalhes sobre as práticas laboratoriais, estimular a excelência ao longo do processo científico, promover discussões mais consistentes em ciência e permitir que um experimento bem documentado (seja qual for o seu status ou resultado) possa ser considerado uma contribuição à ciência.

O caderno aberto de laboratório é um dos elementos de um fluxo de trabalho automatizado que adota formatos abertos e licenças abertas e integra repositórios, blogs, wikis, bancos de dados, ferramentas de busca, e de visualização, queries e aplicativos para estabelecer um ecossistema de colaboração aberta no qual qualquer pessoa (ou sistema automatizado) capaz de realizar contribuições relevantes pode ser considerado um par. Nas palavras de Bradley, "eu não me importo se [as contribuições] provêm de um alguém laureaudo com um Nobel, um precoce de 14 anos ou um bot" (BRADLEY, 12 dez 2006). Em última instância, se propõe como uma extensa plataforma de revisão por pares que amplia a sua escala ao se tornar aberta (a todos e todas), transparente (a vista de todos), contínua (sem data de expiração), interativa (admite réplicas e tréplicas), dinâmica (com novos comentários e retificações ao longo do tempo) e "deseditorializada" (sem controle prévio de um comitê editorial).

Ainda que se configure como prática alternativa, consideramos (CLINIO, ALBAGLI, 2017) que a proposta do caderno aberto de laboratório, preconizada por Jean-Claude Bradley e incorporada por alguns early adopters como o projeto Open Source Malaria, engendra uma nova cultura epistêmica por deslocar a ênfase dos "matter of facts" (fatos científicos) para o que chamamos de "matters of proof". Mais do que a construção de um fato científico irrefutável, a ser comunicado em um artigo científico que narra sua obtenção, valoriza-se a qualidade da documentação disponibilizada para a comunidade científica a partir de práticas baseadas na transparência, na qualidade das evidências e, especialmente, na 
preservação da proveniência de dados (data provenance). Ou seja, no histórico sobre o conjunto dos dados que permite rastrear a origem, as transformações pelas quais foram submetidos, as análises e as interpretações realizadas pelos cientistas ao longo da pesquisa.

\section{Referências}

BRADLEY, J.-C. Remote Controlled Labs. Post publicado no blog UsefulChem em 12 dez 2006. Disponível em <http://usefulchem. blogspot. com.br/2006/12/remote-controlled-labs.html> Acesso em 24 jan 2019.

BRADLEY, J.-C. Open Notebook Science. Post publicado em Drexel COAS E-learning Blog em 26 set 2006. Disponível em <http://drexel-coas-elearning.blogspot.com.br/2006/09/open-notebook-science.html> Acesso em 24 jan 2019.

BRADLEY, J.-C. Interview with Jean-Claude Bradley. The Impact of Open Notebook Science by Richard Poynder. Information Today. Publicado em set. 2010. Disponível em: <http://www.infotoday.com/it/sep10/Poynder. shtm|\#top> Acesso em 24 jan. 2019.

CLINIO, A. Por que open notebook science? Uma aproximação às ideias de Jean Claude-Bradley. In: ALBAGLI, S.; MACIEL, M. L.: ABDO, A. (Org.). Ciência Aberta, Questões Abertas. 1ed.: Ibict, 2015, p. 253-286. Disponível em <http:/livroaberto.ibict.br/handle/1/1060>. Acesso em 19 ago. 2019.

CLINIO, A. Novos cadernos de laboratório e novas culturas epistêmicas: entre a política do experimento e o experimento da política. 2016. 
240 f. Tese (Doutorado) - Curso de Ciência da Informação), Programa de Pós-graduação em Ciência da Informação, Universidade Federal do Rio de Janeiro, Instituto Brasileiro de Informação em Ciência e Tecnologia, Rio de Janeiro, 2016. Disponível em: <http://ridi.ibict.br/bitstream/123456789/943/1/anne_clinio_doutorado_final_14-06-17.pdf>. Acesso em: 19 ago. 2019.

CLINIO, A.; ALBAGLI, S. Open notebook science as an emerging epistemic culture within the Open Science movement. Revue Française des Sciences de L'Information et de la Communication, v. 11, p. -, 2017. Disponível em: <http://journals.openedition.org/rfsic/3186>. Acesso em 19 ago. 2019.

CLINIO, A.; ALBAGLI, S. Cadernos abertos de laboratório e publicações líquidas: novas tecnologias literárias para uma Ciência Aberta. RECIIS: Revista Eletrônica de Comunicação, Informação \& Inovação em Saúde, v. 11, p. 1, 2017. Disponível em: <https://www.reciis.icict.fiocruz.br/index. php/reciis/article/view/1427/pdf1427>. Acesso em 19 ago. 2019.

COMO CITAR: CLINIO, Anne. O caderno aberto de laboratório de Jean-Claude Bradley. In: SHINTAKU, Milton SALES, Luana Farias (Orgs.) Ciência aberta para editores científicos. Botucatu, SP. ABEC, 2019. p. 67-72. DOI: http://dx.doi.org/10.21452/978-85-93910-02-9.cap9 


\section{Fast Track Publication: rapidez na comunicação científica}

Viviane Veiga' ${ }^{18}$

termo fast track, designa um meio mais rápido e mais direto para o alcance de um objetivo. No âmbito da comunicação científica este termo está associado a publicação das descobertas científicas em um modelo mais rápido do que o processo normal. Isto significa que o processo de avaliação neste caso é acelerado. O modelo de fast track ou accelerated publication adotado pelo periódico pode variar, mas em sua maioria, a análise do artigo é realizada por um ou mais editores ou revisores do periódico. Caso o conteúdo do artigo seja considerado de interesse imediato para comunidade científica ou para sociedade, pode ser publicado no modelo fast track. O objetivo é possibilitar disseminação rápida a artigos que apresentam grande contribuição à sua área, apresentando implicações práticas imediatas, ou urgentes.

18 ICICT/FIOCRUZ 
Enquanto o artigo que é submetido no modelo tradicional pode durar até um ano para ser publicado, no modelo de rápida publicação é possível que o artigo esteja disponível em 24hs. Alguns periódicos científicos têm adotado este modelo de publicação, principalmente em situação de emergência.

A publicação acelerada ou fast track publication tem sido adotada há alguns anos. Em 1986 o periódico Biochemistry ${ }^{19}$ publicou comunicado de sua adoção ao modelo de publicação acelerada para artigos que fossem considerados de significância especial e interesse imediato de seus leitores. Estes artigos deveriam ter um formato de comunicação curta, não excedendo 4 páginas.

No campo da saúde alguns periódicos adotaram políticas fast track de forma excepcional ou contínua, como New England Journal of Medicine, The Lancet, British Medical Journal, CMAJ, Journal American Medical Association (JAMA), Science e Nature.

Em 2015, na emergência sanitária vivida pela epidemia de Zika a Organização Mundial de Saúde lançou o Zika Open, um protocolo para a submissão dos resultados das pesquisas no tema, com um fluxo de trabalho diferenciado, disponibilizando os artigos julgados relevantes em 24 horas (ORGANIZAÇÃO MUNDIAL DA SAÚDE, 2015).

Um exemplo de fast track no período de emergência em Zika no Brasil foi o utilizado pelo periódico Memórias do Instituto Oswaldo Cruz, editado pela Fundação Oswaldo Cruz. O Memórias de Oswaldo Cruz criou uma seção chamada "Zika Fast Track", onde foram publicados manuscritos de pesquisa relevantes para a epidemia do Zika (PIRMEZ, 2016).

19 Disponivel em: <https://pubs-acs-org.ez68.periodicos.capes.gov.br/doi/pdf/10.1021/ bi00264a600>. 
O periódico seguiu recomendações do Boletim da Organização Mundial de Saúde (OMS) (Dye et al. 2016) ${ }^{20}$ e disponibilizou o conjunto de dados associados ao documento de forma aberta.

De modo geral, alguns periódicos limitam o número de artigos que serão aceitos por ano no modelo fast track, outros raramente utilizam. Apesar de não haver consenso entre os editores científicos sobre a adoção desta prática de forma regular, a necessidade de se acelerar o processo de revisão por pares de forma que não haja artigos que sejam mantidos em processo de revisão por período superior a um ano é defendida pela comunidade científica. No Brasil a discussão da adoção desta modalidade, na maioria das vezes se esbarra na atribulada agenda do avaliador, que normalmente acumula múltiplas atribuições como professor, orientador, pesquisador, gestor e debilitada infraestrutura de apoio.

Apesar disto, segundo Ghali (2002) os avaliadores experientes utilizam cerca de duas horas revisando um artigo científico, independentemente do prazo estipulado pelo editor. Porém, devido as diversas atividades, muitos avaliadores só conseguem se dedicar a esta tarefa quando o prazo está finalizando.

\section{Referências}

AMERICAN ASSOCIATION FOR THE ADVANCEMENT OF SCIENCE. About Science Express [Website]. Disponível em: < https://stke.sciencemag.org/ content/about-science-express >. Acesso em: 19 ago. 2019.

20 Disponivel em:<https://www.who.int/bulletin/volumes/94/3/16-170860.pdf> 
BIOCHEMISTRY. Accelerated Publication. Biochemistry, v. 21, n. 12, out. 1982. Disponível em: < https://pubs.acs.org/doi/abs/10.1021/ bi00264a600 >. Acesso em: 19 ago. 2019. DOl: 10.1021/bi00264a600.

CANADIAN MEDICAL ASSOCIATION JOURNAL. With all due haste: fast tracking at CMAJ. CMAJ, v. 164, n. 8, p. 1117. Disponivel em: < https:// www.ncbi.nlm.nih.gov/pmc/articles/PMC80951/>. Acesso em: 19 ago. 2019.

DYE, C. et al. Data sharing in public health emergencies: a call to researchers. Bulletin of the World Health Organization, v. 94, n. 3, p. 158-158, 2016.

GHALI, W. A. et al. Accelerated publication versus usual publication in 2 leading medical journals. CMAJ: Canadian Medical Association Journal, [s. I.], v. 166, n. 9, p. 1137-1143, 2002. Disponível em: < https://www.ncbi. nlm.nih.gov/pmc/articles/PMC102352/>. Acesso em: 19 ago. 2019.

GHALI, W.A.; CORNUZ, J. Early uptake of research findings after fast-track publication. The Lancet, [s.I.], v. 355, n. 9203, 2000, p. 579-580. Disponível em: < https://www.ncbi.nlm.nih.gov/pubmed/10683036>. Acesso em: 19 ago. 2019. DOI: 10.1016/S0140-6736(05)73234-7.

GOLDBECK-WOOD, S.; ROBINSON, R. BMJ introduces a fast track system for papers: we will offer to publish exceptional papers within four weeks. BMJ, [S.I.], v. 318, n. 7184, p. 620. Disponível em: <https://www.bmj. com/content/318/7184/620>. Acesso em: 19 ago. 2019. DOI:10.1136/ bmj.318.7184.620.

MCNAMEE, D. Fast-track to publication in The Lancet. The Lancet, v. 351, n. 9102, 1998, p. 542. 580. Disponível em:< https://www. sciencedirect. 
$77 \mathrm{com} /$ science/article/pii/S0140673605785536?via\%3Dihub>. Acesso em: 19 ago. 2019. DOI:10.1016/S0140-6736(05)62891-7.

NATURE. For Author: How to publish your paper: About advance online publication. Disponível em:< https://www.nature.com/authors/author_resources/about_aop.html>. Acesso em: 19 ago. 2019.

ORGANIZAÇÃO MUNDIAL DA SAÚDE (OMS). Developing global norms for sharing data and results during public health emergencies. 2015. Disponível em: <http://www.who.int/medicines/ebola-treatment/blueprint_phe_data-share-results/en/>. Acesso em: 4 abr. 2019.

PIRMEZ, C.; BRANDAO, A. A.; MOMEN, H. Emerging infectious disease and fast-track publication: when public health gets priority over the formality of scholarly publishing. Mem. Inst. Oswaldo Cruz, Rio de Janeiro, v. 111, n. 5, p. 285, 2016. Disponível em: <http://www.scielo.br/scielo.php?script=sci_arttext\&pid=S0074-02762016000500285\&lng=en\& $\mathrm{nrm}=i \mathrm{~s} 0>$. Acesso em 19 ago. 2019. http://dx.doi.org/10.1590/0074-02760160001.

WINKER, M.A; FONTANAROSA, P.B. JAMA-EXPRESS: rapid peer review and publication. JAMA, [S.I], v. 281, n. 18, p. 1754-1755, 1999. Disponível em: < https://jamanetwork.com/journals/jama/fullarticle/189775>. Acesso em: 19 ago. 2019. DOI:10.1001/jama.281.18.1754.

COMO CITAR: VEIGA, Viviane. Fast Track Publication: rapidez na comunicação científica. In: SHINTAKU, Milton; SALES, Luana Farias (Orgs.) Ciência aberta para editores científicos. Botucatu, SP. ABEC, 2019. p. 73-78. DOI: http://dx.doi.org/10.21452/978-85-93910-02-9.cap10 



\section{Plataformas e}

infraestruturas no

contexto da pesquisa

científica

Andre Luiz Appel ${ }^{21}$

iferentemente da ciência da informação que, desde sua gênese, vem atuando em um movimento de consolidação dos seus traçados e limites (PINHEIRO; LOUREIRO, 1995), a comunicação científica, como área de estudo e como prática, segue em uma direção contrária, voltada para a transformação e reconfiguração. Tal fato decorre de sucessivos episódios de crises, inovações tecnológicas (e.g. evolução dos meios eletrônicos) e sociais (e.g. movimentos por software, acesso, ciência, dados abertos), sendo que os fluxos e modelos clássicos da comunicação científica, assim como algumas de suas concepções mais tradicionais ou universais - tais como periódicos e artigos científicos, canais

21 http://orcid.org/0000-0002-9608-803X

Instituto Brasileiro de Informação em Ciência e Tecnologia, Coordenação de Tecnologias Aplicadas a Novos Produtos, Brasília, DF, Brasil 
formais e informais etc. - não têm mais dado conta de enquadrar essas transformações e inovações.

Entram em cena, então, novos conceitos, tais como práticas e objetos científicos, os quais viemos utilizando recorrentemente em lugar das tradicionais formulações de canais e artigos científicos, por exemplo, além das noções de plataformas e infraestruturas de suporte à pesquisa e interação científica. Em contrapartida, agentes do legado da indústria das publicações, em especial as editoras comerciais, atuam num esforço de contrarreação e apropriação dessas inovações, pela proposição e promoção estratégica de novos modelos de negócio.

A concepção mais contemporaneamente utilizada de plataforma remete à noção técnica clássica de software, trazida por Howe (1994), dando suporte a alguma atividade ou tarefa específica. No plano científico-acadêmico, as plataformas suportam conjuntos variados de atividades que incluem, por exemplo, produção de documentos (manuscritos, trabalhos acadêmicos, relatórios de pesquisa etc.), aferições de pareceres, análises de dados, busca, acesso, organização e disseminação de documentos e informações, e infinitas outras.

Conjuntos de plataformas acessíveis de forma remota/via Internet, ou seja, cuja estrutura física - instalações, ambientes de refrigeração, rede física etc. - é desenvolvida, atualizada, provida e mantida por terceiros, ou quando acompanhadas de conjuntos de normas e prescrições compartilhadas (NEYLON, 2017), são por vezes chamadas também de infraestruturas de suporte ou apoio à pesquisa científica.

No plano das infraestruturas públicas ou sem fins lucrativos de suporte à pesquisa, ganham destaque iniciativa recentemente mediada pela UNESCO (2018) para a união de diversas plataformas regionais (AJOL, Amelica, JStage, OpenEditions e SciELO) e a iniciativa do Center for Open 
Science (COS) - sediado em Charlottesville, VA, Estados Unidos - a qual sustenta toda uma ecologia de orientações e serviços voltados para pesquisa e publicações abertas. Já no plano das infraestruturas privadas ou com fins comerciais, destacam-se as ações de organizações como Elsevier/RELX Group, Clarivate Analytics e Digital Science - esta ligada ao grupo Springer Nature -, as quais têm buscado expandir sua oferta de serviços com foco em novas estratégias de mercado e atuação, indo além do tradicional papel de editoras comerciais/publishers e assumindo novas funções ou oferecendo novos serviços no ciclo de pesquisa.

Em relação ao universo das plataformas de suporte à pesquisa, em função da pluralidade de práticas e objetos que elas mobilizam ou abrigam, há diversos potenciais de abordagem dessa temática. Dois eixos ou cenários que podemos destacar são o técnico-funcional e o tecno-político e econômico.

No eixo técnico-funcional, vislumbram-se objetos científicos circulando por diferentes canais ou localizações, assumindo diferentes formatos, em diferentes idiomas e para diferentes públicos, de acordo com diferentes expectativas, necessidades ou usos. Em tal cenário, noções de autoplágio, filtros de produtividade, ranqueamento e avaliação, por exemplo, fazem pouco ou nenhum sentido (ISRAEL, 2019). Vislumbra-se, igualmente, uma transição descomplicada entre formatos, etapas, funções ou serviços do ciclo de pesquisa, com plataformas que amparam desde a criação até a distribuição e circulação de ideias ou resultados de pesquisa.

Kramer e Bosman (2016; 2018) realizaram um esforço abrangente de identificação e sistematização de plataformas e demais ferramentas, por meio do estudo 101 Innovations in Scholarly Communication. Dentre os resultados do estudo, os autores sistematizaram diversos possíveis fluxos de trabalho com base nas ferramentas identificadas, 
categorizando-as em seis grandes grupos de funções apresentadas no Quadro 1. Destacamos que essas categorias e funções são ilustrativas e não se esgotam nos exemplos e vice-versa, pois são agrupamentos que derivam de orientações e usos sociais, característicos desse paradigma de plataforma, em contraste com o cenário tradicional de software e demais produtos e serviços de informação científica distribuídos em formatos "empacotados" ou permanentes.

Quadro 11.1 - Exemplos de categorias ou funções de plataformas de apoio à pesquisa.

\begin{tabular}{|c|c|c|}
\hline $\begin{array}{l}\text { Categoria ou } \\
\text { função }\end{array}$ & Descrição & Exemplos \\
\hline descoberta & $\begin{array}{l}\text { dão suporte à pesquisa e descoberta de artigos } \\
\text { e demais documentos científicos, possibilitan- } \\
\text { do a pesquisa em bases de dados de textos } \\
\text { completos ou de metadados de publicações }\end{array}$ & $\begin{array}{l}\text { Mendeley, Web of } \\
\text { Science, SciELO }\end{array}$ \\
\hline análise & $\begin{array}{l}\text { disponibilizam ferramentas e infraestrutura } \\
\text { para tratamento e análise de dados }\end{array}$ & $\begin{array}{l}\text { GitHub, iPython } \\
\text { Notebooks, } \\
\text { MatLab, Jupyter }\end{array}$ \\
\hline $\begin{array}{l}\text { escrita; } \\
\text { criação }\end{array}$ & $\begin{array}{l}\text { oferecem funcionalidades por meio das quais } \\
\text { autores podem criar textos, manuscritos, re- } \\
\text { gistros científicos etc., diretamente na Web, via } \\
\text { plataformas, de forma individual ou colabora- } \\
\text { tiva (simultaneamente), com finalidade ou não } \\
\text { de publicação, sendo que algumas plataformas } \\
\text { oferecem possibilidades de criação de regis- } \\
\text { tros científicos que extrapolam o textual, com } \\
\text { a incorporação de dados e linguagens de mar- } \\
\text { cação ou programação ao longo dos registros }\end{array}$ & $\begin{array}{l}\text { Google Docs/ } \\
\text { Drive, Overleaf, } \\
\text { Authorea, Jupyter } \\
\text { Notebook }\end{array}$ \\
\hline publicação & $\begin{array}{l}\text { viabilizam a publicação de textos na forma de } \\
\text { notas, manuscritos, preprints, artigos, dados, } \\
\text { código ou software, além de diversos outros } \\
\text { objetos }\end{array}$ & $\begin{array}{l}\text { OSF Preprints, } \\
\text { PeerJ, Zenodo, } \\
\text { Figshare, GitHub }\end{array}$ \\
\hline
\end{tabular}



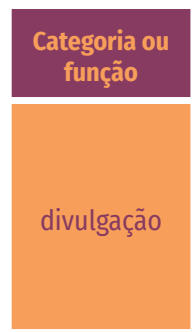

avaliação

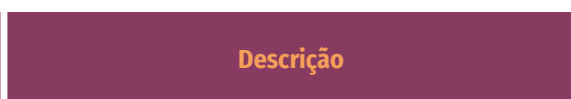

viabilizam a disseminação e promoção de textos ou objetos publicados em outras plataformas, a exemplo de redes sociais acadêmicas e não acadêmicas, criação de perfis, além de interação entre integrantes da comunidade científica

viabilizam a avaliação do impacto, alcance, audiência de textos e demais objetos publicados em outras plataformas
Exemplos

ORCID, Research

Gate, Mendeley,

Twitter

Fonte: elaboração própria com base em Kramer e Bosman (2018).

Em relação ao eixo tecno-político e econômico, ressaltam-se as preocupações ou considerações acerca da governança e das formas de organização e compartilhamento dessas plataformas e infraestruturas (NEYLON, 2017). Considerações estas que se fazem importantes, uma vez que tem se demonstrado que avanços da economia de plataformas no cenário acadêmico potencializam novos riscos de oligopolização, controle exógeno e puramente orientado a fins comerciais da definição de temas e metodologias de pesquisa (POSADA; CHEN, 2018), ações de vigilância e exploração comercial de dados pessoais (OLIVEIRA, 2018; PARRA; CRUZ; AMIEL; MACHADO, 2018; SMITH, 2015) e a algoritmização das relações e da tomada de decisão no contexto acadêmico (GONZÁLEZ DE GÓMEZ, 2013; INTRONA, 2016).

\section{Referências}

GONZÁLEZ DE GÓMEZ, M. N. Sobre normas e algoritmos: os critérios de validade da ciência e da informação. In: ENCONTRO NACIONAL DE PESQUISA EM CIÊNCIA DA INFORMAÇÃO, 14., 2013, Florianópolis, SC. 
Anais... . Florianópolis, SC: Ancib; UFSC. 2013. Disponível em: http:// repositorio.ibict.br/handle/123456789/463. Acesso em: 1 nov. 2015.

HOWE, D. Platform. FOLDOC: Free On-line Dictionary of Computing. 12 jul. 1994. Disponível em: http://foldoc.org/platform. Acesso em: 22 fev. 2019.

INTRONA, L. D. Algorithms, Governance, and Governmentality: On Governing Academic Writing. Science, Technology \& Human Values, v. 41, n. 1, p. 17-49, 2016. Disponível em: http://dx.doi. org/10.1177/0162243915587360.

ISRAEL, M. Self-plagiarism: When is re-purposing text ethically justifiable? LSE Impact [Blog]. 27 fev. 2019. Disponível em: https://blogs.Ise. ac.uk/impactofsocialsciences/2019/02/27/self-plagiarism-when-is-re-purposing-text-ethically-justifiable/. Acesso em: 27 fev. 2019.

KRAMER, B.; BOSMAN, J. 101 Innovations in Scholarly Communication. Innovations in Scholarly Communication [Site]. 2018. Disponível em: https://101 innovations.wordpress.com/. Acesso em: 22 fev. 2019.

KRAMER, B.; BOSMAN, J. Innovations in scholarly communication: global survey on research tool usage. F1000Research, v. 5, p. 692, 18 abr. 2016. Disponível em: https://f1000research.com/articles/5-692/v1.

NEYLON, C. Sustaining Scholarly Infrastructures through Collective Action: The Lessons that Olson can Teach us. KULA: knowledge creation, dissemination, and preservation studies, v. 1, n. 1, p. 3, 2017. Disponível em: http://doi.org/10.5334/kula.7. Acesso em: 12 jun. 2019.

OLIVEIRA, T. M. de. Mediatization of science: reconfigurations of the paradigm of scientific communication and academic labour in digital 
era. MATRIZes, v. 12, n. 3, p. 101-126, 2018. Disponível em: http://www. revistas.usp.br/matrizes/article/view/147868.

PARRA, H.; CRUZ, L.; AMIEL, T.; MACHADO, J. Infraestruturas, economia e política informacional: o caso do Google Suite for Education. Mediações: Revista de Ciências Sociais, v. 23, n. 1, p. 63, 6 jul. 2018. Disponível em: https://doi.org/10.5433/2176-6665.2018v23n1p63.

PINHEIRO, L. V. R.; LOUREIRO, J. M. M. Traçados e limites da ciência da informação. Ciência da Informação, v. 24, n. 1, 1995. Disponível em: <http://revista.ibict.br/ciinf/article/view/609>. Acesso em: 12 jun. 2019.

SMITH, D. Surveillance and the Scholarly World: what shall we do with the database of intentions? The Scholarly Kitchen [Blog]. 23 jun. 2015. Disponível em: https://scholarlykitchen.sspnet.org/2015/06/23/ surveillance-and-the-scholarly-world-what-shall-we-do-with-the-database-of-intentions/. Acesso em: 15 jan. 2016.

UNESCO. Launch of the Global Alliance of Open Access Scholarly Communication Platforms to democratize knowledge. UNESCO [Site]. 12 abr. 2019. Disponível em: https://en.unesco.org/news/launch-global-alliance-open-access-scholarly-communication-platforms-democratize-knowledge. Acesso em: 24 abr. 2019.

COMO CITAR: APPEL, Andre Luiz. Plataformas e infraestruturas no contexto da pesquisa científica. In: SHINTAKU, Milton; SALES, Luana Farias (Orgs.) Ciência aberta para editores científicos. Botucatu, SP. ABEC, 2019. p. 79-86. DOI: http://dx.doi.org/10.21452/978-85-93910-02-9.cap11 



\title{
12 Publicações
}

\section{semânticas: melhorando}

comunicação entre

\section{homem e máquina}

\author{
Luana Sales
}

Rosali Fernandez de Souza

- ntre os novos modelos de publicação que se apresenta como opção no mundo contemporâneo da comunicação científica, uma proposta interessante é o que vem sendo chamado na literatura de Publicações Semânticas. Esse modelo visa "combinar documentos e ontologias permitindo que usuários acessem o conhecimento de várias maneiras" (ERICKSON, 2007a). Ao adicionar anotações padronizadas por meio de ontologias aos documentos digitais, estes documentos se tornam mais semânticos sendo possível melhorar a precisão da informação recuperada, processar conhecimento de forma automatizada e ainda gerar novos serviços. 
Outra definição de publicações semânticas é a de Shotton (2009) que afırma ser esta

qualquer coisa que melhore o significado de um artigo de periódico publicado, facilite a sua descoberta automatizada, permite a sua ligação com os artigos semanticamente relacionados, fornece acesso a dados dentro do artigo em forma de recurso, ou facilite a integração de dados entre os artigos.

Para Shotton, a semântica do documento se dá a partir da contextualização da publicação. Essa contextualização pode ser feita de diversas maneiras, inclusive a partir da disponibilização dos dados relacionados ao conteúdo do documento.

Nesic (2010), em contraposição à definição de Erickson (2007a), afırma que este conceito deveria denotar não apenas documentos anotados com ontologia e sim uma nova categoria de documentos que pudesse contribuir plenamente com o ambiente idealizado pela Web semântica. Para Nesic, um documento semântico deve ser construído com base em quatro princípios: 10 conteúdo do documento deve ser completamente consultável, com elementos endereçáveis e de granularidade diferentes; 2 Todo o documento deve ser identificado exclusivamente com URIs (Uniform Resource Identifiers); 3 Todo o documento deve ser anotado com conjuntos substanciais de metadados; 40 conhecimento humano expresso no documento deve ser também representado de uma forma que possa ser processado por máquinas (isto é, os agentes de software);

Nesic (2010) recomenda a partir desses princípios uma nova definição para os documentos semânticos, a saber: "recurso composto unicamente identificado e semanticamente anotado". Para ele, o recurso composto é formado por unidades menores que também devem ser Identificadas e anotadas semanticamente. Assim, o autor propõe um modelo semântico 
de documento caracterizado por ter conteúdo (dados) e conhecimento representados nele de forma compreensível para humanos e agentes de software. Cada documento pode possuir diferentes tipos de relacionamentos com outros documentos ou com outros recursos (páginas Web, instituições, dados, etc) também devidamente identificados por suas URIs. Para definir a estrutura lógica do documento são utilizadas relações hierárquicas entre seus componentes.

Assim como o modelo de Nesic (2009), existem outras iniciativas de criação de publicação semântica, cada uma seguindo em uma direção, mas todas com o mesmo objetivo de melhorar a capacidade das publicações digitais de transmitirem conhecimento e significado. Marcondes (2011), por exemplo, propõe um modelo de publicação em que a semântica é explicitada no próprio texto do documento, isto é, nas conclusões que são fornecidas pelos autores e representadas em formato legível por máquina permitindo recuperação semântica e descoberta de novos conhecimentos. Outro exemplo é o modelo proposto por Erickson (2007b) em que a semântica é adicionada ao documento a partir de anotações feitas com base em uma ontologia OWL, assim, os conceitos existentes no documento são ligados à ontologia permitindo ao usuário alternar entre a navegação do documento e a ontologia.

Shotton (2009) também apresenta um modelo semântico de publicação em que o enriquecimento do conteúdo da publicação se dá por meio de acesso às bases de dados inclusas no documento. O modelo compreende marcação semântica de termos textuais, com links para outros recursos de informação relevantes, números interativos, lista de referência reordenável, resumo do documento que contém síntese do estudo, uma nuvem de tags e análise de citação. O modelo inclui ainda dois novos tipos de enriquecimento semântico: o primeiro, dicas para permitir "citações no contexto" e o segundo, uma taxonomia que reúne termos semanticamente relacionados. Além disso, publicam planilhas 
de dados e figuras para download, com as devidas informações de procedência, e demonstram vários tipos de fusão de dados (mashups), com os resultados de outros artigos de pesquisa e com o Google Maps.

Enquanto os modelos semânticos de Marcondes e Erickson acima citados se preocupam com a padronização para a melhoria da recuperação, o modelo de Shotton (2009), apesar de toda a sua sofisticação, permanece na extração de significado via contexto.

A definição de Shotton (2009) é relevante, pois caminha na direção do modelo de publicação ampliada semântica, onde os dados devem ser ligados às publicações com base em alguma semântica. Neste caso, a ideia é que o modelo se utilize da contextualização proporcionada pela adição de recursos como os sugeridos por Shotton (marcação semântica, link para dados de pesquisa, resumo com sínteses etc), mas que também se utilize da padronização descritiva e terminológica promovida pelo uso de metadados e pelo controle do vocabulário e suas relações.

Percebe-se então a preocupação da maioria das iniciativas com questões referentes à precisão da informação recuperada ou com o conhecimento processado. Além disso, tanto o uso de tecnologias semânticas quanto o uso de ontologias integram as novas propostas de publicação ao mundo da Web Semântica onde interoperabilidade e resposta precisa a questões de busca são desejáveis para potencializar o uso da Web.

\section{Referências}

ERIKSSON, H. An annotation tool for semantic documents. Lecture Notes in Computer Science, v. 4519, p. 759-768, 2007a. Disponível em: 
< https://link.springer.com/chapter/10.1007/978-3-540-72667-8_54 >. Acesso em: 19 ago. 2019.

ERIKSSON, H. The semantic-document approach to combining documents and ontologies. International Journal of Human-Computer Studies, v. 65, n. 7, p. 624-639, 2007b. Disponível em: < https://www.sciencedirect.com/ science/article/pii/S1071581907000468>. Acesso em: 19 ago. 2019.

MARCONDES, C. H. Um modelo semântico de publicações eletrônicas. Liinc em Revista, v. 7, n. 1, 2011. Disponível em: < http://revista.ibict.br/ liinc/article/view/3290>. Acesso em: 19 ago. 2019.

NEŠIĆ, S. Semantic document model to enhance data and knowledge interoperability. In: DEVEDŽIC, V.; GAŠEVIC, D. (Eds.). Web 2.0 e Semantic Web. Holanda: Springer, 2009, p. 135-160. (Annals of Information Systems, v. 6). Disponível em: < https://link.springer.com/chapter/10.1007/978-1-4419-1219-0_6>. Acesso em: 19 ago. 2019.

NEŠIĆ, S. et al. Search and Navigation in Semantically Integrated Document Collections. In: SEMAPRO 2010: THE FOURTH INTERNATIONAL CONFERENCE ON ADVANCES IN SEMANTIC PROCESSING, 4., 2010, Florência. Proceedings... . Florência: Iaria, 2010. p. 55-60. Disponível em: < https://thinkmind. org/index.php?view=article\&articleid=semapro_2010_3_20_50040>. Acesso em: 19 ago. 2019.

SHOTTON, D. Semantic publishing: the concept the coming revolution in scientific journal publishing. Learned publishing, v.22, n.2, p. 85-94, 2009. Disponível em: < https://journals.plos.org/ploscompbiol/article?id=10.1371/journal.pcbi.1000361 >. Acesso em: 19 ago. 2019. DOI: 10.1371/journal.pcbi.1000361. 



\section{Ciência Aberta e Mídias do Conhecimento}

Ronnie Fagundes de Brito

Milton Shintaku

Ciência Aberta vislumbra um novo conjunto de princípios e práticas associados ao fazer científico, sendo um modo inovador de pensar a pesquisa e que afeta desde o planejamento à divulgação de seus resultados, ou mesmo o uso do conhecimento tornado público. Nesse sentido, cabe o raciocínio de que se muda a prática, as tecnologias que as apoiam também mudam, visto que são ferramentas que apoiam as atividades. Da mesma forma que novas tecnologias pode alterar práticas, tornando-as mais eficazes. Assim, torna-se um ciclo contínuo, interativo e realimentado de mudanças nos fazeres associados a atividade científica e as ferramentas que a apoiam.

A Ciência Aberta é ampla, tanto que Albagli, Maciel e Abdo (2015) definem como um guarda-chuva, abarcando diversas frentes, que transcende a disseminação livre dos resultados de pesquisa. Por isso, as ferramentas que a apoiam são diversificadas alinhando-se aos conceitos de mídias do conhecimento, defendido por Eisenstadt e Vincent (1999) como o uso de várias ferramentas para apoiar o processo de geração, compreensão e compartilhamento de conhecimento. 
Explicitando, ferramentas, tecnologias, software, interfaces, padrões e formatos são conceitos associados entre si, os quais pode-se denominar de mídias, pois são os meios pelo quais aqueles que fazem ciência registram e comunicam seus resultados, enviando-os por distâncias ou armazenando-os no tempo. É possível refinar o conceito de mídia ao aplicar princípios das ciências cognitivas associados a práticas de gestão do conhecimento a esses recursos tecnológicos, permitindo melhor adequação das ferramentas aos seus usuários e seus objetivos, gerando o que se denomina mídias do conhecimento.

Nesse contexto, relacionado às frentes da Ciência Aberta com as Mídias do Conhecimento, pode-se ter a seguinte lista, que mesmo não extensiva, ajuda a ter uma visão geral do ambiente tecnológico e conceitual:

a. Acesso Aberto aos resultados de pesquisa: publicações de acesso abertos já são comuns e em grande parte do Brasil utilizam o Open Journal System (OJS) ou seus correspondentes para Anais de congressos o Open Conference System (OCS) e o Open Monograph Press (OMP) para livros. Repositórios digitais facilitam o acesso e podem ser implementados com o EPrints, DSpace ou mesmo o OMEKA;

b. Dados Abertos de pesquisa: os dados de pesquisas devem ser depositados em repositórios institucionais implementados com EPrins ou com ferramentas mais voltadas a dados como o Dataverse ou o CKAN;

c. Hardware Aberto de pesquisa: esse ponto tem relação com conceitos de maker e DIY (Do It Yourself), no qual a sua construção é autoral, como no caso do projeto Arduino. Entretanto, há iniciativas como o ao Safecast e o Air Quality Egg no qual os desenhos do hardware são abertos. 
d. Cadernos Científicos Abertos: são formas de compartilhamento de procedimentos efetuados na pesquisa, como nas narrativas possíveis no Jupyter Science Notebook ou Open Notebook Science Network, pode ser blogs científicos com o Hypotheses.

e. Ciência Cidadã: Esse ponto pode ser implementado com ferramentas para a construção colaborativa, no chamado crowdsourcing, como a wikipedia, implementado com o midiawiki. Outro meio de colaboração é o Open Science Framework (OSF), ou mesmo em caso de softwares o Github.

f. Aprendizagem aberta: o caso mais emblemático desta frente se representa no Moodle, com utilização de padrões como o Learning Object Metadata (LOM) e o Shareable Content Object Reference Model (SCORM). Entretanto, há outras frentes como o Open Science MOOC e o projeto SLOOP.

A Ciência Aberta é mais ampla do que as frentes apresentadas, assim como as mídias. Assim, o presente relato não se propõe a ser extenso ou aprofundado visto a proposta do livro, mas apresentar um panorama básico relacionando as mídias do conhecimento as práticas da Ciência Aberta. Apresenta-se como um resultado preliminar e inicial do mapeamento das mídias que podem ser utilizadas nas diversas frentes da Ciência Aberta. 


\section{Referências}

ALBAGLI, S.; MACIEL, M. L.; ABDO, A. H. (Orgs.). Ciência aberta, questões abertas. Brasília: Ibict, 2015. p. 9-25. Disponível em: < http://livroaberto. ibict.br/handle/1/1060 >. Acesso em: 21 ago. 2019

EISENSTADT, M.; VINCENT, T. The knowledge web: Learning and collaborating on the web. Inglaterra: Kogan Page Ltd, 1999. 328 p. 


\title{
14 Periódicos de
}

\section{resultados negativos:} revelando uma parte invisível da ciência

\author{
Luis Fernando Sayão
}

Luana Farias Sales

ciência é, por natureza, um empreendimento colaborativo que percorre em uma trajetória dialética de erros e acertos, cujos processos e interlocuções, fundamentados no método científico, vão pouco a pouco convergindo para novos conhecimentos e descobertas. Esse diálogo está mais evidente no ciclo contínuo de confrontos e rupturas que historicamente acontece entre os paradigmas prevalentes e a inevitabilidade das novas ideias. Quando nos colocamos num ponto de observação epistemologicamente mais amplo, a importância dos resultados negativos para o progresso da ciência tem os contornos mais nítidos. Isto porque, são os achados negativos que resultam na rejeição de hipóteses que impulsionam a ciência e que ficam registradas nos seus anais como um catalisador da revolução científica e também como um elogio a refutação. 
No cotidiano dos laboratórios os resultados negativos - resultados não confirmatórios e nulos, experimentos inconclusivos, dados inesperados, etc. - permeiam todo o ciclo da pesquisa, e constituem uma parte importante da integralidade dos fluxos de pesquisa. Os projetos científicos raramente resultam em descobertas perfeitas de elementos sobre o universo, a natureza e a sociedade. Isto acontece porque, conforme destacam Anderson et al (2013), as pesquisas são frequentemente baseadas em métodos com limitações reais, modelos experimentais imperfeitos e hipóteses baseadas em premissas incertas, que desafiam o tempo todo o poder de autocorreção da ciência e os princípios de reprodutibilidade dos experimentos científicos. Porém, mesmo considerando essas situações de incertezas e negatividade por onde caminha a ciência, em muitos casos, os procedimentos, fluxos e metodologias são rigorosamente corretos, mas levam a becos sem saída, cujos percursos precisam ser documentados, avaliados, publicados e compartilhados para que outros pesquisadores não percorram o mesmo caminho ou para que suas metodologias sejam aperfeiçoadas.

"Resultados nulos, negativos ou inesperados são ocorrências possíveis para pesquisadores em todo o mundo" (GUIMARÃES et al, 2018). Entretanto, a perspectiva triunfalista da ciência, que se volta de forma privilegiada para os produtos finais da pesquisa - o invento, o artigo, a patente, a tese - condena à obscuridade tudo que não é sucesso e que está inconcluso. Como consequência, deixa sem registro uma parte importante dos labirintos trilhados pelos cientistas, e cria, muitas vezes, um conflito com a integridade e objetividade do processo de pesquisa, forçado pelo viés positivo da ciência ou do interesse de por algum de seus atores, como editores e financiadores, por resultados positivos (FANELLI, 2010; FANELLI, 2012). Assim sendo, os resultados de milhares de experimentos não confirmatórios jamais verão a luz do dia e permanecerão para sempre nos cadernos de laboratórios, gavetas e pen drives onde serão, inevitavelmente, tragados pelo tempo. 
Esse panorama, induzido pelo viés de resultados positivos, tem um rebatimento claro nos fluxos de comunicação científica, mais especificamente nas publicações acadêmicas, que somente em alguns casos aceitam resultados negativos, sob o argumento, muitas vezes duvidoso, do baixo impacto desses relatos. Essa condição, por sua vez, influência nos parâmetros de avaliação e recompensa definidos pelas instituições de fomento à pesquisa, que deixam de lado as contribuições à ciência dos relatos dos experimentos que não deram certo, e criam uma lacuna na memória acadêmica das instituições de pesquisa. Em um ambiente que tem como um dos pilares a concorrência e a vaidade, é de se esperar que os periódicos científicos prefiram publicar estudos com conclusões e produtos específicos e claros que garantam mais citações; e que os pesquisadores relutem em expor seus supostos fracassos que gerem questionamentos e incertezas.

Mas há uma perspectiva de mudança no ar. Não obstante as circunstâncias muitas vezes contrárias e os debates e controvérsias em torno dessas questões, emerge na ciência o reconhecimento de que a publicação de resultados negativos pode contribuir grandemente para o progresso da ciência, quando expõe um panorama mais realístico da natureza errática dos percursos da ciência. "Pode-se argumentar que os 'dados negativos', longe de terem pouco valor para a ciência, são atualmente uma parte integral do progresso científico que merecem mais atenção", destaca Anderson e seus colaboradores (2013, p.1), sinalizando a necessidade de incorporação desses resultados aos esquemas acadêmicos de publicação e reconhecimento.

Nessa direção, a compreensão de que é necessário para o progresso da ciência a publicação e o compartilhamento de resultados negativos se tornam cada vez mais comum em várias comunidades científicas. Como desdobramento dessa nova percepção, um crescente número de periódicos dedicados a este tipo de resultados tem surgido no cenário 
editorial acadêmico. Podemos classificar, então, os periódicos científicos segundo as suas políticas de aceitação de resultados negativos em quatro categorias: os periódicos que não aceitam resultados negativos; os que aceitam; os que publicam números especiais sobre dados negativos e, finalmente os que são dedicados a esses resultados. Há ainda alguns repositórios dedicados ou que aceitam dados negativos, como, por exemplo, o F1000Research Open for Science' ${ }^{1}$.

O principal e mais óbvio benéfico de publicar resultados negativos é redução na duplicação de esforços - em termos de tempo, recursos e esforço intelectual - evitando que outros pesquisadores trilhem caminho que se mostraram inviáveis. Contudo, podemos relacionar outros benefícios como, por exemplo: maior transparência e abertura dos processos e fluxos científicos; integralidade da memória científica e valorização do potencial disruptivo dos experimentos não confirmatórios. Portanto, não registrar os achados negativos configura um estreitamento das fronteiras da transparência científica e dos pressupostos da ciência aberta.

\section{Referências}

ANDERSON, G.; SPROTT, H.; OLSEN, B. Opinion: Publish negative results. The Scientists, jun. 15, 2013. Disponível em: <https://www.the-scientist. com/opinion/opinion-publish-negative-results-39928>. Acesso em 06 agosto 2019.

FANELLI, D. Do pressures to publish increase scientists' bias? An empirical support from US States Data. PlosOne, n.5, 2010. Disponível em: <https://

1 Disponivel em: <https://f1000research.com/>. Acesso em: 09 set. 2019. 
journals.plos.org/plosone/article?id=10.1371/journal.pone.0010271 >. Acesso em 06 ago. 2019.

FANELLI, D. Negative results are disappearing from most disciplines and countries. Scientometrics, v. 90, n. 3, p. 891-904, 2012. Disponível em: $<$ https://link.springer.com/article/10.1007/s11192-011-0494-7>. Acesso em 06 ago. 2019.

GUIMARÃES, R. et al. Negative results in scientific research: ethical aspects. Revista Bioética, v. 26, n. 2, 2018. Disponível em: <http://www. scielo.br/scielo.php?pid=\$1983-80422018000200245\&script=sci_arttext>. Acesso em 06 ago. 2019. 



\section{Publicações \\ científicas ampliadas}

Adriana Carla Silva de Oliveira²

s mudanças ocorridas nas últimas décadas proporcionaram grandes transformações na sociedade contemporânea. Reflexo também na ciência e no processo de comunicação científica. As novas formas de concepção, disseminação, acesso e uso das informações foram remodeladas.

Garvey e Griffith (1979), afırmam que tais mudanças são significativas e de profundas transformações na comunicação científica. Associa um conjunto de atividades à produção, disseminação e uso da informação. Para Gasque (2008, p. 30), "a ciência e tecnologia têm sido responsáveis pelas grandes transformações pela qual a humanidade passa, alterando ainda de forma desigual, o cotidiano das pessoas".

Na contemporaneidade, o estado da arte da ciência moderna está sendo alterado pelo seu modo de fazer e publicar a investigação científica. A comunicação científica, que por séculos foi apoiada pela cultura impressa, tornando acessível apenas os resultados finais de pesquisa, foi repensada a partir de movimentos mundiais, como o Open Access, a Open Science e a Data Science. Tais movimentos provocaram alterações

2 Pós-Doutora em Direito pela UFRN. Doutora em Ciência da Informação pela Universidade Federal da Paraíba. Mestre em Engenharia de Produção pela UFRN. Graduada em Direito e Bacharel em Biblioteconomia. Professora colaboradora da UFRN. Natal - Rio Grande do Norte - Brasil. E-mail: adrianacarla.a@gmail.com. 
na geração, gestão e disseminação das publicações científicas, inicialmente impressas, e agora fortemente na modalidade digital e eletrônica.

Novos horizontes vislumbram a Ciência Aberta como a modalidade de pesquisa aberta e colaborativa, que pressupõe transformações nas práticas científicas tradicionais, na qual determina os dados de pesquisa como produtos primários, com propósito único de promover a investigação científica de forma coletiva, colaborativa, inovadora e sustentável (OLIVEIRA, 2019).

Ademais, com o quarto paradigma científico além dos dados de pesquisa "fica patente que a adição de outros recursos ao texto, como imagens, sons e interatividade, agora se torna fundamental" (SALES, 2013, p. 3473). Assim, na práxis científica da e-Science é imperativo um novo modelo de publicação que se utilize das tecnologias e recursos abertos, de redes de conectividade e interatividade para a geração dos novos fluxos de dados, informações e publicações.

Esse novo gênero de publicação científica denominamos de publicação ampliada. Denominada internacionalmente como Enhanced Publication $(E P)$, e caracterizada, como uma maneira totalmente nova de publicação científica tradicional (um livro, um artigo ou um relatório), se define com o enriquecimento de informações e objetos digitais adicionais. Portanto, a Enhanced Publication é uma publicação reforçada, melhorada, sobreposta, que possibilita a interatividade, a conectividade e a convergência de todas as partes da pesquisa. Além do processo investigativo, é possível a conexão numa mesma interface, de informações de pesquisadores, grupos de pesquisas, agências de fomento e instituições de ensino e pesquisa. Parte da premissa que a publicação nos moldes tradicionais "gutenberguianos' já não atende a atual Sociedade da Informação. 
No Brasil, a experiência que merece destaque é o modelo E-prints ampliados por dados de pesquisa apresentado na Figura 15.1.

Figura 15.1 - E-prints ampliados por dados de pesquisa

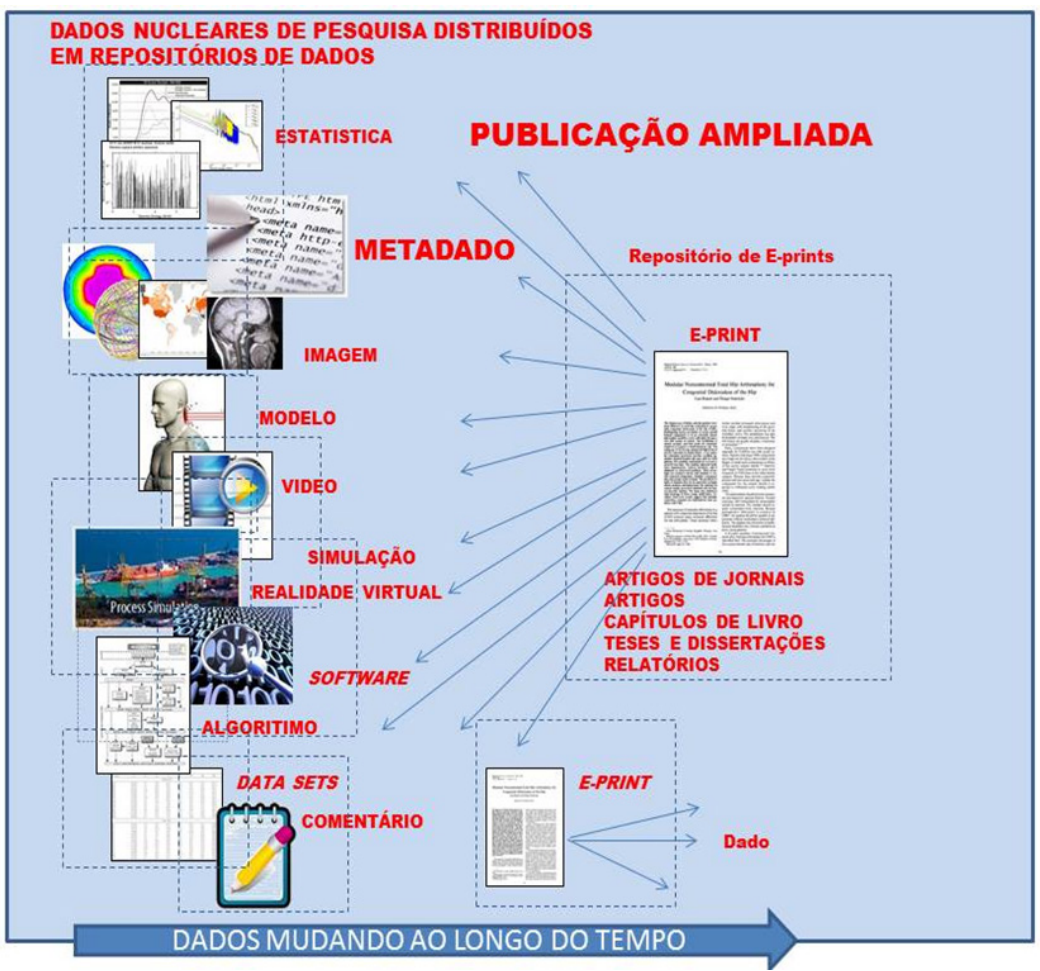

Fonte: SALES; SAYÃO; SOUZA (2013).

O modelo é uma completa representação de publicação ampliada que agrega além das partes relacionadas ao conteúdo outras modalidades de publicações, como artigos, capítulos de livros, teses e dissertações, dentre outros. Possibilita também, a interoperabilidade com repositórios de dados, com o acesso a diferentes objetos digitais e seus respectivos 
metadados. Consiste em uma representação de generalização do processo de ampliação, considerando os dados da pesquisa em diferentes espaços temporais e distribuídos nos repositórios de dados, indicando a possibilidade de versionamento da publicação e de seus componentes.

Em suma, a busca por modelos que integrem além dos artigos convencionais, os dados brutos, documentos, anotações de pesquisa e outros objetos digitais, se faz necessário para a nova ambiência digital e compartilhada da ciência. As possibilidades e alternativas proporcionadas com o uso das tecnologias de informação e comunicação impulsionam cada vez mais a investigação científica moderna. Utilizar todo o potencial dos dados de pesquisa, promovendo a gestão, a curadoria e a preservação digital a longo prazo é a nova forma de realizar a pesquisa científica contemporânea.

\section{Referências}

GARVEY, W. D.; GRIFFITH, B. C. Scientific communication as a social system. In: GARVEY, W. D.; GRIFFITH, B. C. Communication: the essence of science. London: Pergamon Press, 1979. p. 148-164.

GASQUE, K. C. G. D. 0 pensamento reflexivo na busca e no uso da informação na comunicação científıca. Brasília: Universidade de Brasília, 2008. 240 p. Tese (Doutorado - Universidade de Brasília) - Departamento de Ciência da Informação e Documentação, Universidade de Brasília, 2008.

OLIVEIRA, A. S. de O. Desvendando a autoralidade colaborativa na e-science sob a ótica dos direitos de propriedade intelectual. 2016. 
300 f. Tese (Doutorado em Ciência da Informação) - Universidade Federal da Paraíba, João Pessoa, 2016. Disponível em:<https://repositorio.ufpb. br/jspui/handle/tede/8849>. Acesso em: 17 jun. 2019.

OPENAIRE. What is a Enhanced Publication?. 2012. Disponível em: <http://www. openaire.eu/en/component/content/article/76-highlights/344-a-short-introduction-to- enhanced-publications>. Acesso em: 06 dez. 2018.

SALES, L. F.; SAYÃO, L. F.; SOUZA, R. F. Publicações ampliadas: um novo modelo de publicação acadêmica para o ambiente de e-science. In: In: ENCONTRO NACIONAL DE PESQUISA EM ClêNCIA DA INFORMAÇÃO, 14., 2013, Florianópolis. Anais... . Florianópolis: Enancib, 2013. Disponível em: <http://eprints.rclis.org/20665/1/publica\%C3\%A7\%C3\%B5es_ampliadas_2013.pdf>. Acesso em: 09 set. 2019.

COMO CITAR: OLIVEIRA, Adriana Carla Silva de. Publicações científicas ampliadas. In: SHINTAKU, Milton; SALES, Luana Farias (Orgs.) Ciência aberta para editores científicos. Botucatu, SP. ABEC, 2019. p. 103-107. DOI: http://dx.doi.org/10.21452/978-85-93910-02-9.cap15 
São Paulo

2019 
O movimento da Ciência Aberta é amplo e abarca múltiplas facetas para o desenvolvimento científico pois impacta também áreas tradicionalmente estabelecidas como a editoração científica. Mostra-se como uma evolução estabelecendo novos paradigmas para a comunicação científica, a partir das mudanças nas tecnologias da informação e comunicação, trazendo desafios e oportunidades para a ciência na contemporaneidade. Diante deste novo cenário, a Associação Brasileira de Editores Científicos (ABEC Brasil) atende ao desfio proposto no Compromisso pela Ciência Aberta, conforme a sexta meta do $4^{\circ}$ Plano da Ação Nacional de Governo Aberto do Brasil, a qual objetiva a articulação com os editores científicos por modelos abertos de ciência. Essa obra é um dos resultados deste esforço, apresentando textos curtos e simples, porém bem fundamentados, visando apoiar os editores, permitedo-lhes conhecer melhor o movimento, que é mundial, e as suas diversas ramificações que envolvem o processo de editoração científica. Contribui ainda com a formação contínua dos editores científicos, diante das mudanças impostas pela digitalização da informação.

Rui Seabra Ferreira Jr

Presidente da ABEC Brasil 